Aus der chirurgischen Privatklinik des Herrn Prof. Tavel und dem physiologischen Institut des Herrn Prof. Kroneker in Bern.

\title{
Experimentell-chirurgischer Beitrag zur Lehre vom Mechanismus der Analsphinkteren.
}

\section{C̈ber die funktionelle Abhängigkeit des Sphincter ani internus rom Sphincter ani externus, nebst Bemerkungen zur Inner- vationsfrage.}

Von Dr. Hermann Matti, Privatdozent für Chirurgie an der Universität Bern.

In vorliegender Arbeit bringen wir, gestützt auf experimentelle Studien am Hunde, die wir auf Anregung von Prof. Ir. Tavel anstellten, einen Beitrag zur Lehre von der Funktion der Analsphinkteren.

Es konnte sich für den Nichtphysiologen von vornherein nicht darum handeln, eingehende Nachuntersuchungen über die Innervation des glatten und quergestreiften Analschließers, speziell über den genauen Verlauf der zentripetalen und zentrifugalen, für den Rektalverschluß und für den Defäkationsmechanismus in Betracht kommenden Bahnen anzustellen; wir begnügten uns in dieser Hinsicht, d. h. soweit wir die Frage berühren mußten, wesentlich mit der Berücksichtigung der reichlichen, einschlägigen Literatur, namentlich der maßgebenden Untersuchungen von Langley und Anderson, Fellner, Pal, Goltz, Merzbacher u. a., sowie besonders der eingehenden Darstellung, welche die gesamte Innervationsfrage des Rektums in der wertvollen Arbeit von L. v. Frank lHochwart und Alfred Fröhlich: „Über Tonus und Innervation der Sphinkteren des Anus" erfährt. Die Abklärung der verschiedenen und zahlreichen, bezüglich der Sphinkterinnervation noch bestehenden Kontroversen bleibt naturgemäß in erster Linie den Physiologen vom Fach vorbehalten; doch sind selbstverständlich auch klinische Beobachtungen unter Umständen geeignet, Licht in die zum Teil noch etwas dunkeln Verhältnisse der Sphinkterinnervation zu bringen, und gerade eine der neueren Arbeiten, die allgemeine Beachtung fand und die sich mit dem Nachweis eines 
extraspinalen Steuerungsapparates für die Blasen und Mastdarmfunktion beschäftigt, verdanken wir einem Kliniker; wir beziehen uns auf die Publikation von L. R. Müller, in der Zeitschrift für Nervenheilkunde, Bd. 21, Heft 1 und 2. Auch die hier vorliegende Arbeit geht von klinischen Beobachtungen am Menschen aus, die eine Anwendung auf die Physiologie des Sphinktermechanismus direkt nahelegten, und zwar handelt es sich unı klinische Erfahrungen über eine auffällige funktionelle Abhängigkeit des glatten Sphincter ani internus vom quergestreiften Sphincter externus. Soweit wir uns orientieren konnten, haben diese Verhältnisse in der Literatur bisher keine klare und genügende Würdigung gefunden, so daß es lohnend schien, die bezüglichen klinischen Erhebungen experimentell am Tier nachzuprüfen, um, soweit möglich, eine Erklärung des zur Untersuchung stehenden Phänomens zu geben.

Zunächst seien die klinischen Beobachtungen am Menschen, durch welche eine experimentelle Untersuchung der vorliegenden Frage veranlaßt wurde, an Hand einiger Krankengeschichten, die Herr Prof. Tavel uns gütigst zur Verfügung stellte, in Kürze wiedergegeben. Wir lassen die betreffenden Krankengeschichten auszugsweise folgen, um die interessierenden Punkte dann zusammenfassend $\mathrm{zu}$ diskutieren.

\section{Krankengeschichten.}

Fall 1. Frau W. F., 28 jährig. Nov. 1897. Nr. 979.

Patientin war immer gesund; fruher ziemlich fett; seit 3 Jahren verheiratet. Vor zwei Jahren Partus, schwere Zange mit DammriB. Seit dieser Geburt hat sie ständig abgenommen und hat Beschwerden von einer rechtseitigen Wanderniere und von einer partiellen Incontinentia alvi und einer Rektovaginalfistel. Wenn Patientin verstopft, der Stuhl also konsistent ist, kann der Stuhl gut gehalten werden. Sobald aber der Stubl dunn ist, hat Patientin "Diarrhöe", wie sie sich ausdruckt, kann der Stuhl nicht zuruckgehalten werden und geht teilweise auch durch die Vagina ab.

Status: Kleine, magere Frau; Lungen und Herz in Ordnung. Leber normal. Rechte Niere läßt sich in die Fossa iliaca interna herunterdracken, ist wenig empfindlich. Uterus retrovertiert. Zwischen Rehtum und Vagina nur eine dünne Scheidewand, ans der Vaginal- und Rektalwand bestehend, ohne jede Interposition von Muskeln.

Es wird in Aussicht genommen, in zwei Sitzungen die Nephropexie und die Plastik der Rektovaginalfistel zu machen.

26. XI. 1897. Operation in guter Âthernarkose. Da die Nephropexie ziemlich schnell ausgefuhrt werden kann, werden beide Operationen in einer Sitzung vorgenommen. Die Fistel wird excidiert, dann von einem Bogenschnitt am Perineum aus Reltum und Vagina voneinander getrennt. Die Öffnung im Rektum wird quer vernăht, dann die freigelegten 
sämtlichen Muskelpartien (Sphincter ani externus) zusammengezogen und mit Katgut vernäht. Darüber werden die Vaginalwundränder längs vereinigt.

Heilungsverlauf ohne jede Störung. Maximale Temperatur 37,6 - Puls 76 bis 96 - Prima Heilung beider Wunden.

Die Funktion des Sphinkter ist eine normale. Die Patientin kann den Stuhl jetzt wieder gut halten.

Fall 2. Herr 0. I. 54jährig. Sept. 1899. Nr. 1481.

Patient hat im Jahre 1887 einen Tripper gehabt, der nur sehr langsam ausheilte. Kurze Zeit nachher schon hatte er eine Striktur, die progressiv dilatiert wurde, dann aber wieder vernachlüssigt. Im September 1899 bekommt Patient plötzlicli hohen 'Temperaturanstieg. Schwellung am Perineum, schlechter Allgemeinzustand. Am 10. IX. incidiert Dr. C. den AbszeB, am 14. IX. werden noch mehrere Fisteln gespalten. Am 15. IX. wird Patient in Konsultation gesehen. Im Zimmer herrscht ein penetranter Geruch nach Naceration und Kot; aus den Fisteln fließt eine schwärzliche Janche mit Fettropfen und Gasblasen. (Bakteriolog. Befund: Coli, Streptokokken, Proteus, keine Anacroben.) Es besteht keine Kommunikation zwischen Rektum und periurethralem Abszeß. Mit zwei seitlichen Schnitten werden die Abszeße breit incidiert und große Mengen nekrotischen Gewebes herausbefördert (ca. $200 \mathrm{gr}$, entsprechend einer vollständigen Nekrose des Zellgewebes der Fossa ischio-rectalis. Irrigation der Abszeßhoble mit Calium hypermangan. 1/500. Patient erholt sich bald. Am 1. X. wird dann eine Urethrotomia interna gemacht und eine Sonde it demeure Nélaton Nr. 11, eingelegt. Verlauf gut. Im Laufe des Frühjahres 1900 klagt Pat. beständig über Darmstörungen. Er hat konstant „Diarrhöe", und man vermutet ein Darmcarcinom. Bei einer Untersuchung in Narkose, im April 1900, kann kein positiver objektiver Befund erhoben werden. Wăhrend der Jahre 1900, 1901 und ersten Hälfte 1902 hat Patient sehr starke Beschwerden von seiten des Stuhles. Wenn Patient nicht große Dosen Laudanum nimmt, kann er keinen Stuhl halten. Am Vormittag hat er gewöhnlich 4-5 Stuhlentleerungen nacheinander. Die Stuhle kommen ganz unerwartet, so daß Patient aus erklärlichen Gründen seinen Geschäften nicht nachgehen kann. Von Zeit zu Zeit hat er Anfälle, die mit Frost beginnen, von heftigen Bauchschmerzen und Diarrhöen gefolgt sind und mit Fieber einhergehen. Der Urin ist während dieser Attacken trüber als gewöhnlich. Die Anfälle dauern zwei bis drei Tage. Nachher fahlt sich Patient wieder fur einige Zeit wohl. Patient konsultiert die ersten medizinischen Autoritäten, welche übereinstimmend einen „rezidivierenden Darmkartarrh" ${ }^{\text {" }}$ diagnostizieren. Eine im Juli 1902 vorgenommene Untersuchung des Urins ergab bakteriologisch eine große Menge Friedländer, sowie Streptokokken in kleiner Quantität.

Die Rektaluntersuchung ergab eine mangelhafte Funktion des Sphincter ani.

Die Diagnose wurde auf einen Blasenkatarrh mit periodischer Ascension nach dem Nierenbecken und intermittierender Pyelitis gestellt. Patient wird mit innerlichen Mitteln behandelt (Salol, Urotropin usw.); anschließend eine Badekur, alles ohne Erfolg. Dann wurden Injektionen von AntiFriedländerserum gemacht, ebenfalls mit negativem Resultat. Nach einer Behandlung mit regelmäBigen Blasenspalungen und Injektionen von 
Argentum nitricum in die Blase verschwanden dann die Anfälle vollständig. Nur die mangelhafte Funktion des Analsphinkters plagte Patienten noch sehr stark.

Am 14. Juli 1904 wird konstatiert, daß der Blasenurin klar ist. Dagegen befindet sich immer noch eine Tasche in der Prostatagegend, aus der sich Eiter ausdrücken läßt. Im Dezember 1904 ist diese Prostataeiterung nach regelmäBigen Spülungen und Sondierungen vollständig ausgeheilt; der Urin ist klar. - Allgemeinzustand sehr gut; keine Anfälle mehr. Dagegen muß Patient immer noch jeden 'Iag am Morgen $4-5 \mathrm{mal}$ seinen Stuhl entleeren und hat meistens nicht Zeit, auf den Abort zu gehen, da er durch den unvermittelt austretenden Stuhl überrascht wird. Deshalb muB er immer groBe Dosen Laudanum nehmen.

5. VII. 1904. Nach genauer Untersuchung läBt sich feststellen, daB der vordere und rechte Teil des Sphincter ani externus fehlt. Der Anus ist gut geschlossen, wenn Patient in der Steinschnittlage liegt. Aber sobald man den Finger in das Rektum einführt, erschlafft der Sphincter internus vollständig, und bleibt, solange der untersuchende Finger im Rektum liegt, vollständig schlaff. Der Anus klafft. Erst nach einigen Minuten schlieBt sich der Sphincter internus wieder ron selbst. Patient ist aber nicht imstande, irgendwie selbst dazu beizutragen.

Infolge dieser Beobachtung wird Plastik des Sphincter externus vorgeschlagen und am 16. I. 1905 in guter Morphium- $̈$ thernarkose ausgefahrt.

Operation: Bogenschnitt am Damm, wie für die Excisio prostatae. Ein Finger kontrolliert vom Rektum aus die Arbeit zur Vermeidung einer Verletzung des Darms. Die Gewebe werden dann ziemlich weit seitlich abpräpariert und die aufgesuchten Stümpfe des Sphincter externus vorne zusammengenäht. Das Rektum wird nicht verletzt. (Zur Technik: Gummihandschuhschutz der linken Hand, während die Präparation mit der rechten Hand ausgeführt wird; dann Ablegen des Handschuhs und Fortsetzung der Arbeit bimanuell.) Drainage. Bogenschnitt durch Dreiecknaht geschlossen (partielle Sagittalnaht), und auf diese Weise werden auch die oberflächlichen Gewebe von der Seite her zusammengenäht.

Heilung p. pr. int. Aus der Drainstelle flieBt noch während einigen Tagen schwarzes Blut, aber nie eine Spur von Eiter. Maximale Temperatur 37,0 , Puls nie uber 80 . Patient wird während $1 \dot{0}$ Tagen mit Laudanum gestopft gehalten.

Am 6. II. 1905 wird die Funktion des Sphinkter kontrolliert.

Wenn man den Finger ins Rektum einfahrt und dem Patienten kommandiert, seinen After zusammenzuziehen, so fühlt man eine schwache Kontraktion des ganzen Sphinkters, auch des vorderen Teils. Der Sphincter internus behält jetzt seinen Tonus, auch wenn der Patient nicht willkürlich kontrahiert. Es findet kein Klaffen des Anus mehr statt nach Einführung des Fingers.

Seither war die Funktion der RektalschlieBmuskeln stets tadellos, und obgleich die Schlußfähigkeit der Sphinkteren, speziell des Sphincter ani externus, entschieden schwächer ist als normal, kann Patient seinen Stuhl nach der eigenen Angabe jetzt wieder zuruckhalten wie früher.

Fall 3. Frau v. G., 31 jährig. Juni 1907. Nr. 3960.

Patientin hat sich mit 25 Jahren verheiratet. Erste Geburt mit 
26 Jahren, zweite Geburt mit 30 Jahren. Bei der ersten Geburt starker Dammriß, der zusammengenäht wurde. Die Naht hielt; aber seit dieser Zeit hat Patientin eine große Schwäche des Rektums bzw. der Analschließmuskeln zurückbehalten. Anfänglich mußte sie nur 2-3 mal am Morgen zur Stuhlentlecrung gehen, und war nachher ruhig, während sie in letzter Zeit jeden Morgen 6-8 Stühle hat. Die Patient sieht sehr schwach und angegriffen aus, teilweise jedenfalls aus psychischen Gründen.

Status, 14. VI. 1907. Patientin ist eine magere, aber nicht anämische Frau. Iunge und Herz in Ordnung. Am $\Lambda$ bdomen nichts Abnormes. Zwischen Vagina und Rektum eine außerordentlich dünne Scheidewand, die nicht dicker ist als dunner Karton. Man fühlt den Sphinkter rechts weiter hinten als links, vorn gar nicht. Es besteht keine Möglichkeit einer willkürlichen Kontraktion. Sobald der Finger eingefuhrt wird, klafft der Anus, der sonst leicht geschlossen ist.

Operation, 14. VI. 1907: Morphium-Scopalamin-Äthernarkose; gut. Dauer 2 Stunden. Querschnitt; die Scheidewand zwischen Rektum und Vagina wird mit groBer Mühe gespalten. Die Spaltung gestaltet sich sehr mühsam wegen der Dünnheit der Wand und wegen der narbigen Verwachsung zwischen Rektal- und Vaginalschleimbaut. Von einem Sphincter internus ist gar nichts mehr vorhanden, geschweige denn von einem Sphincter externus. Eine kleine Verletzung der Rektalschleimhaut wird sofort mit ganz feinem Katgut vernäht; darüber noch eine Lage Bindegewebe vereinigt. Die Dissektion wird ca. $5-6 \mathrm{~cm}$ nach hinten bzw. nach oben fortgefuhrt, bis zu einer Stelle, wo Rektum und Vagina nicht mehr miteinander verwachsen sind.

Die Rektalwand wird dann seitlich präpariert, bis man auf die gat erkennbaren Sphinkterstumpfe kommt, die dann unter großer Muhe und mit ziemlich starker Spannung zusammengebracht werden. Dadurch werden auch die Winkel der äußeren Wunde so zusammengezogen, daß es ratsam erscheint, den Querschnitt lăngs zu vernähen. Keine Drainage.

In den ersten Tagen bleibt die Wundo ganz reaktionslos; Temperatur an den zwei ersten Tagen abends 37,9 und 37,8 , von da an Temperatur ganz normal. Entfernung der Nähte am 14. Juni. Dabei fließt etwas seröses Sekret. Diese Sekretion dauert bis 5. Juli, an welchem Tage vollständige Heilung der Wunde notiert wird. Patientin wird vom 14. bis 29. Juni verstopft gehalten; von da an bekommt sie täglich ein Klysma. Die Klysmen können jetzt ganz gut gehalten werden; auf jedes erfolgt ein leichter Stuhl.

Am 18. Juli wird der Damm von Vagina und Rektum aus untersucht; seine Dicke beträgt $2 \frac{1}{2} \mathrm{~cm}$ bis in eine Tiefe von $3 \mathrm{~cm}$.

28. VIII. 1907. Nachuntersuchung: Die wiederhergestellte Wand zwischen Rektum und Vagina ist vollkommen fest; das Perineum ist ca. $3 \mathrm{~cm}$ hoch und einem normalen fast gleich. Patientin hat gar keine Beschwerden mehr gehabt; sie iBt mit gutem Appetit und fuhlt sich wohl. Gegenuber dem normalen Zustand vor der ersten Geburt ist hinsichtlich Funktion der Analsphinkteren kein Unterschied zu konstatieren (Angabe der Patientin). Auf Kommando wird der Sphinkter leicht kontrahiert; der Anus klafft nicht mehr, wenn man den Finger eingefuhrt hat. - Die Heilung erwies sich als eine dauernde. 
Die vorliegenden Krankengeschichten beziehen sich auf 3 Fälle von partieller Incontinentia alvi infolge anatomischer Läsion des Musculus sphincter ani externus; im Fall Nr. 3 war offenbar auch der glatte Sphincter internus anatomisch nicht mehr intakt. Bei allen Patienten war jedenfalls die ringförmige Kontinuität des äußeren Analsphinkters unterbrochen, während eine Störung der Innervation nicht in Frage kam. Es fiel zunächst auf, daß alle diese Patienten über "Diarrhöen" klagten, obschon, wie die Erhebung einer genaneren Anamnese, die nähere Untersuchung und die Spitalbeobachtung ergab, keine Diarrhöen im gewöhnlichen Sinne des Wortes vorlagen; die Verhältnisse waren vielmehr so, daß die Patienten festen, geformten Stuhl eine Zeitlang halten konnten, während breiförmige und dünne Stühle stets zu unerwarteten, plötzlichen Stuhlentleerungen Anlaß gaben, durch welche die Patienten oft sehr unangenehm überrascht wurden. Gewöhnlich wiederholten sich diese lästigen, „sturzweisen“ Stuhlentleerungen, namentlich am Morgen, mehrmals hintereinander in ganz kurzen Intervallen. So bekamen die Patienten den Eindruck, an hartnäckigen Diarrhöen zu leiden, während eine ursächliche chronische Erkrankung des Darms bei keinem Kranken vorlag. Es handelte sich nicht um "Diarrhöe", sondern um partielle Rektalinkontinenz; die lokale Untersuchung ergab mit Sicherheit, daß der geschilderte Symptomenkomplex einzig und allein auf der mechanischen Insuffizienz der Analsphinkteren beruhte. Besonders instruktiv in dieser Hinsicht ist Fall 2, der jahrelang von Autoritäten an rezidivierendem Darmkatarrh behandelt wurde, während, wie die objektive Untersuchung und namentlich der Effekt der Operation lehrte, einzig das pathologische Verhalten der Analsphinkteren für die Symptome von seiten des Darms verantwortlich zu machen war.

Die lokale Untersuchung zeigte bei allen Patienten, daß der Anus - inspektorisch - gut geschlossen war; sobald man jedoch den untersuchenden Finger in das Rektum einführte, erschlafte der Sphincter internus, der allein in seiner zirkulären Kontinuität erhalten war, sofort auffällig, und auch der unterste Teil des Rektums, also die Pars perinealis, wurde rasch vollkommen atonisch. Nach dem Herausziehen des Fingers klaffte der After, so daß man direkt in die untersten Partien des Mastdarmlumens hineinblicken konnte; erst nach einigen Minuten war der Sphincter internus wieder vollständig kontrahiert und der Anus geschlossen. - Durch die direkte Palpation überzengte man sich auch von dem partiellen Defekt des Sphincter externus. 
Bei allen Patienten wurde in Erkenntnis der ursächlichen Läsion eine Plastik, d. h. eine möglichste Rekonstruktion des Sphincter externus ausgeführt, indem man die normalen anatomischen Verhältnisse, so gut es eben noch möglich war, operativ wiederherstellte. Die wesentlichste Leistung der Operation bestand jeweilen in der präparatorischen Freilegung der Stümpfe des Sphincter externus, welche durch einige Katgutsuturen vereinigt wurden, so daß wieder ein kontinuierlicher Sphincter-externus-Ring das Darmrohr, bzw. den Sphincter internus umschloß. Dals dabei nur relativ unbedeutende Muskelpartien im Vergleich zu dem kräftigen normalen Sphincter externus zur Vereinigung gelangten, ist klar, wenn man die Schwierigkeiten der Präparation in dem starren Narbengewebe bedenkt, und ferner in Betracht zieht, daß der Sphincter externus durch Inaktivitätsatrophie jeweilen schon stark gelitten hatte. - Die quere Incision am Darm wurde bei Fall 2 partiell in sagittaler Richtung vernäht, bei Fall 3 wurde der quer angelegte Hautschnitt vollkommen in der Längsrichtung geschlossen. Dieser Dammplastik, welcher von einigen Autoren für die Besserung des Analschlusses in Fällen von lokal bedingter Rektalinkontinenz eine bedeutende Wirkung zugeschrieben wird, kommt wohl bei unseren Patienten ein wesentlicher Anteil am Erfolg der Operation nicht zul ${ }^{1}$. Wie wir sehen werden, ist der unmittelbare, überraschend bedeutende Operationseffekt, der bei allen 3 Patienten zu konstatieren war, der Plastik des Sphincter externus zuzuschreiben. Die Nachuntersuchung ergab übereinstimmend bei allen Patienten, daß der Analschluß ein wesentlich kräftigerer war, als vor der Operation, d. h. der eingeführte Finger mußte einen energischeren Sphinkterverschluß überwinden. Nach Einführung des Fingers in das Rektum behielt der Analring, also auch der Sphincter internus, seinen 'Tonus; es trat weder eine Erschlaffung des Analrings, noch eine Atonie des untersten Rektalabschnitts ein. Ebenso auffällig war, daß der Anus nach dem Zurückziehen des untersuchenden Fingers nicht mehr klaffte, sondern sich sofort wieder gut und kräftig schloß. Während ferner die Patienten vor der Operation keine noch so minimale Andeutung einer willkürlichen Sphinkterkontraktion gezeigt hatten, erfolgte jetzt auf Kommando stets eine dentliche, wenn auch nicht

1) Sie wurde auch nur aus dem Grunde gemacht, weil durch die Zusammenziehung der Sphinkterstümpfe auch die seitlichen Wundwinkel einander genähert wurden, und durch die sagittale Vereinigung der queren Incision eine für den definitiven Operationseffekt wertvolle Entspannung erzielt wurde. Die Sphinkternaht erhielt so größere Sicherheit. 
besonders kräftige willkürliche Zusammenziehung des Sphincter ani, zum Beweise, daß die Plastik des Externus geglückt war. Entsprechend diesem lokalen Untersuchungsbefund, der eine ganz erhebliche Besserung des Analschlusses, genauer betrachtet, eine prinzipielle Umkehrung des vor der Operation beobachteten Mechanismus des Sphincter internus bedeutete, waren die Erscheinungen der partiellen Inkontinenz und damit die sog. „Diarrhöen" vom ersten Stuhle an völlig verschwunden. Die Patienten konnten ihren Stuhl. ob derselbe feste, breiförmige oder dünnflüssige Konsistenz hatte, wieder in nornaler Weise halten, sogar Klysmen, und waren so durch die, im Grunde genommen, ziemlich unvollkommene Plastik des Sphincter externus dauernd von ihrer lästigen Inkontinenz befreit und damit aus einem wirklich kläclichen Zustand erlöst.

Wie schon erwähnt, betrachten wir die Rekonstruktion des Sphincter externus als wesentlichen Akt der ausgeführten plastischen Operationen, während wir der bei Fall 2 und 3 angeschlossenen Dammplastik nur untergeordnete Bedeutung beimessen. Mit dieser Ansicht stimmit die Beobachtung überein, daß man von den zahlreichen plastischen Operationen, welche zur Hebung mangelhafter Sphinkteraktion angegeben wurden, wie die Tabaksbeutelnaht (Dupuytren) Keilexcision (Dieffenbach, König) Einlegen eines Silberdrahtrings (Thiersch) Drehung des Rektums um seine Längsachse (Gersuny) allmählich zu Methoden übergegangen ist, welche ihren Angriffspunkt wesentlich in den Sphincter externus verlegen, von der richtigen Frwägung ausgehend, daß eine ätiologisch begründete Therapie die besten Heilungschancen bietet. So berichten namentlich Kehrer und Helferich (Bilfinger) über selr günstige funktionelle Resultate mit ihrer Methode der Sphinkterfaltung, bz.w. Sphinkterverdoppelung durch partielles Übereinanderschieben des Sphincter externus. / $\mathrm{u}$ dieser Kategorie von Operationen gehört auch die von Hofmann für die Behandlung des Mastdarmvorfalls angegebene Methode, bei der allerdings neben der Verengerung des Sphinkterrings noch eine Verschiebung desselben nach vorne sowie eine Verlängerung des Beckenbodens erzielt wird. Gegenüber diesen Methoden, bei denen ein in seiner Kontinuität intakter Sphinkter einfach gekürzt, somit der Sphinkterring verengert wird, fällt als wesentlicher Unterschied beim Tavelschen Verfahren auf, daß hier nur relativ unbedeutende Partien des Sphincter externus über dem Darmende zirkulär vereinigt wurden; trotzdem war der Operationseffekt ein geradezu idealer. Es mulite auffallen, daß durch das Zusammenziehen einiger Fasern des 
Sphincter externus ein so total verschiedenes Verhalten des Analschlußrings, besonders des Sphincter internus, veranlaßt wurde. Der direkte mechanische Gewinn durch Wiederherstellung eines schwachen Externusrings und anschließende Dammplastik stand in einem offenbaren Mißverhältnis zur Besserung des Analschlusses, der nach der Operation in allen Fällen so ziemlich der physiologischen Norm entsprach. Besonders in die Augen springend war das differente Verhalten des glatten Sphincter internus vor und nach der Operation: vor der Operation sofortige Relaxation auf Fingereinführung, Klaffen des Sphinkterrings nach Zurückziehen des Fingers, - nach der Operation Auslösung einer kräftigen, andauernden tonischen Kontraktion des Sphincter internus, nach Zurückziehen des untersuchenden Fingers kein Klaffen des Rektums mehr, sondern sofortiger, guter Analschluß.

Zunächst stand also fest, daß eine einfache Plastik eines Bruchteils Sphincter externus eine völlige Umgestaltung im Verhalten des Sphincter internus zur Folge hatte. Damit war erklärt, warum der relativ geringe Zuwachs an Externusfasern genügte, um die mechanische Kraft des Analrings so weit zu steigern, daß wieder völlige Kontinenz vorhanden war. Die direkte Beobachtung, durch welche das prinzipiell veränderte Verhalten des Sphincter internus - und übrigens auch der Pars perinealis des Mastdarms nach der Operation konstatiert war, sowie einfache Überlegung ergaben, daß es nicht allein der mechanische Zuwachs an einigen, dem Willen unterworfenen Fasern des Sphincter externus war, der die Patienten wieder kontinent machte, sondern wesentlich die durch diesen minimalen Zuwachs an Externusfasern bediugte durchgreifende Änderung im Verhalten des glatten Analsphinkters und des Enddarms.

Diese Erscheinung konnte verschiedene Erklärungen haben. Vorerst fragte es sich, ob die veränderte Aktion des Sphincter internus durch einfache Veränderung der mechanischen Verhältnisse bedingt sein konnte. Sodann kam die Möglichkeit in Betracht, daß durch den reflektorisch zur Kontraktion angeregten Externusring der Sphincter internus direkt mechanisch an der Relaxation verhindert werde. Auch konnte man sich denken, daß der Internus durch die Kontraktion des Externus direkt zur aktiven Zusammenziehung angeregt wurde - eine Auffassung, die wir an andern Orten wiederfinden und später noch eingehend diskutieren werden - oder daß durch die Kontraktion des Sphincter externus auf dem Umwege intramuskulärer (oder außerhalb des Darms befindlicher 
[sympathischer]) „Reflexbahnen" der Sphincter internus zu andauernder tonischer Schließkontraktion angeregt werde. Für diese letztern Anschauungen finden sich Anhaltspunkte sowohl in der physiologischen wie in der klinischen Literatur (Landois, L. R. Müller).

Da nun das interessante Phänomen, soviel wir sehen, in der physiologischen Literatur noch gar nicht gewürdigt ist, und zudem die praktische Wichtigkeit der vorbeschriebenen Erscheinung gerade für den Chirurgen und Gynäkologen außer Zweifel steht, lag es nahe, zunächst auf operativem Wege experimentell bei einem Versuchstier die Verhältnisse herzustellen, wie sie bei den angeführten klinischen Fällen vorgelegen hatten, ${ }^{*}$ um dann, falls sich das differente Verhalten des Sphincter internus bei intaktem oder in seiner Kontinuität getrennten Externus auch im Tierversuch bestätigen sollte, auf ein genaueres experimentelles Studium der Frage einzutreten.

Als Versuchstiere wählten wir Hunde, da einmal mit Rücksicht auf die beabsichtigte Präparation des Sphincter ani eine gewisse Größe des Versuchsobjektes wünschenswert erschien. Sodann bot uns bei der Wahl dieses Tieres die eingehende Arbeit von v. Frankl-Hochwart und A. Fröhlich eine wertvolle und willkommene Basis. Zudem wurde auch die Mehrzahl der maßgebenden experimentellen Arbeiten, die wir zu berücksichtigen hatten, am Hunde ausgeführt. Da ferner gleich das erste Experiment, welches wir gleichsam als entscheidenden Vorversuch anstellten - Trennung und nachherige Rekonstruktion des Sphincter externus - also Nachahmung der beschriebenen klinischen Fälle, in allen Einzelheiten übereinstimmend ausfiel, hielten wir uns für berechtigt, am Hunde weiter zu experimentieren und die gewonnenen Resultate unter gewissen Reserven auf den Menschen zu übertragen. Wir können, was die vorliegende Frage betrifft, von der differenten Innervation und von den Abweichungen, welche der Verlauf der sog. Auxiliärmuskeln (Levator ani, Cocygens, Schweifmuskeln) beim Hunde darbieten, füglich absehen, ohne daß die Sicherheit der Rückschlüsse auf den Menschen in prinzipiell wichtigen Punkten eine Einbuße erleidet, wie die folgenden Experimente zeigen werden. Wir haben natürlich alle in Betracht fallenden Fehlerquellen, die anatomischen Abweichungen betreffend, nach Möglichkeit bei der jeweiligen Versuchsanordnung in Betracht gezogen.

Wir lassen nun vorerst eine Besprechung der Versuchsergebnisse folgen, soweit sie die Frage der funktionellen Abhängigkeit des 
Sphincter internus vom Sphincter externus betreffen, das eigentliche Thema unserer Arbeit. Mit der Frage der Innervation beschäftigten wir uns experimentell nur in zweiter Linie, soweit es nötig war, um in prinzipiellen und wichtigen Fragen ein Urteil ans eigener Anschauung zu gewinnen.

Versuchsergebnisse.

Bevor wir an die Ausführung unserer Tierexperimente gingen, stellten wir zu genauerer Orientierung eine Anzahl von Präparaten her, an welchen sowohl die Muskulatur des Beckenbodens als auch die Innervation des Rektums und seiner Sphinkteren anatomisch dargestellt wurden. Bezüglich der Muskeln stützten wir uns auf die deskriptive Anatomie des Hundes von Ellenberger und Baum, bezüglich der Innervation auf die zusammenfassende - zum Teil auf eigene Untersuchungen der Autoren basierte - Darstellung von L. v. Frankl-Hochwart und A. Fröhlich. Wir verweisen deshalb auf diese ausführlichen Publikationen, mit deren Resultaten sich die Ergebnisse unsrer eigenen Untersuchungen in allen wesentlichen Punkten decken. Wir können deshalb gleich zur Besprechung der Experimente (deren ausführliche Protokolle sich im Anhang beigegeben finden) und der Versuchsergebnisse übergehen.

Zunächst handelte es sich darum, einem Hunde den Sphincter externus obne Nebenverletzung zu trennen, um zu sehen, ob sich der Sphincter internus in seinen Funktionen gleich verhalte, wie es beim Menschen mit teilweise zerstörtem äußeren Sphinkter konstatiert worden war. Dann sollte durch operative Wiedervereinigung des Sphincter externus die Norm soweit möglich wieder hergestellt werden, um festzustellen, ob die Aktion des glatten Sphinkter dadurch eine Änderung erleide. Vom Ausgang dieses Vorexperiments hing es ab, ob die angeschnittene Frage überhaupt durch Versuche am Hund der Abklärung entgegengeführt werden könne.

Es erwies sich als praktisch, den Sphincter externus zu beiden Seiten des Anus von einem etwa 1 bis $1 \frac{1}{1} \mathrm{~cm}$ lateral vom Analsaum angelegten Bogenschnitt ans freizulegen, und jede, sorgfältig isolierte Sphinkterhälfte separat zu trennen. Finseitige 'Trennung hätte den Nachteil gehabt, daß durch Kontraktion der andern Muskelhälfte das Rektum seitlich zusammengepreßt und so ein gewisser Analschluß hergestellt worden wäre (wie wir mehrmals intra operat. konstatierten). T'rennung in der vordern oder hintern Sagit- 
talen bedingte $z u$ hochgradige anatomische Läsion, da nur die aborale Partie des Sphincter externus den Anus ringartig umschließt, während die mittlere und orale Partie des Muskels, wie die aborale von der Schweifaponeurose entspringend, zentralwärts in den gleichseitigen M. bulbocavernosus bzw. in den Constrictor cunni ausstrahlt. Es ist also leicht ersichtlich, daß die seitliche Trennung des Externus mit sehr viel geringerer Nebenverletzung möglich war, als die Abtrennung von der Schweifaponeurose oder vom M. bulbocavernosus. So folgten wir für die Freilegung des Sphincter externus der schon von v. Frankl-Hochwart und Fröhlich benutzten Technik: Bogenschnitt beidseitig lateral vom Anus, Abpräparieren des Fettes der Fossa ischio-rectalis von der AulBenfläche des äußjern Sphinkter. Fingehen nach oben zwischen Lavator ani und Sphincter externus (orale Portion). Stumpfe Ablösung der Fasern des Spincter externus vom Rektum, mit Kropfsonde oder Präpariernadel, am obern Rande des Externus beginnend, eventuell Gegenpräparation vom untern Rande des äußern Schlielsers her. Erleichtert wird die Abgrenzung des Sphincter externus gegen den Sphincter internus durch den beidseitig $z$ wischen glattem und quergestreiftem Sphinkter eingelagerten Analbentel. Nach gehöriger, aber möglichst umschriebener Isolierung wurde der Sphincter externus zu beiden Seiten quer durchtrennt, unter sorgfältiger Vermeidung einer Verletzung des Nervus pudendus und namentlich des $\mathbf{N}$. haemorrhoidalis medius. Aus diesem Grunde wurde die 'Trennungslinie stets dorsalwärts vom Nerven verlegt, der sich an der Grenze von ventralem und mittlerem Drittel in den Sphinkter einsenkt. - Da der glatte Sphincter internus keinen so prompten blitzartigen Reflex auf Reizung der Rektalschleimhaut oder der perianalen Hautpartien gibt, wie der Sphincter externus, war es leicht, allfällig noch stehengebliebene Fasern des letztern durch Auslösung des Reflexes zur Kontraktion zu bringen und unter Leitung des Auges und gleichzeitiger Kontrolle durch einen ins Rektum eingeführten Finger nachträglich noch zu trennen. So glauben wir eine genaue Trennung des Sphincter externus unter Vermeidung einer Verletzung des Sphincter internus auch an den Stellen erreicht zu haben, wo beide Muskeln innigere Beziehungen zueinander eingehen. In dieser Weise wurde bei Versuchstier Nr. 1 der Sphincter externns beidseitig getrennt und nachher die Wunde sorgfältig geschlossen. Nach der Operation konstatierte man, daß am Anus ein ${ }^{1}: 2 \mathrm{~cm}$ breiter Saum von Rektalmucosa sichtbar geworden war, ohne daß der After offen stand, indem der kontrahierte Sphincter internus den Abschluß des Rektums immer 
noch besorgte. Das Sichtbarwerden dieses Rektalschleimhautsaums beruht darauf, daß auch beim Hunde der Sphincter externus etwas weiter unten liegt, als der Sphincter internus, $d . h$. daß der Sphincter internus nach unten hin um einige Millimeter vom äußern Sphinkter überragt wird. Sobald der Externus nicht mehr schlußfähig ist, tritt der entsprechende Schleimhautsaum zutage. Dabei verhindert aber der gut kontrahierte Sphincter internus den direkten Einblick in das Rektum. - Schon die erste Untersuchung am Tage nach der Operation zeigte nun, daß die tonische Kontraktion des Sphincter internus einige Sekunden nach Einführung eines Fingers ins Rektum sich löst, und daß auch die oberhalb des glatten Schließers befindlichen Partien der Rektalwand dem untersuchenden Finger dann nur noch atonisch anliegen. Eine eigentliche Dilatationsbewegung des Rektums konnten wir nicht feststellen. Nach Entfernung des Fingers klafft der After ganz kurze Zeit, um sich dann wieder gut zu schließen. Auch bei allen spätern Nachuntersuchungen zeigt sich, daß bei diesem Versuchstier die tonische Kontraktion des Sphincter internus und der Rektalwandmuskulatur (auch eines angedeuteten Sphincter tertius), die bei Einführung des untersuchenden Fingers konstatiert wird, sich schon nach 15 bis 20 Sekunden löst, und in Atonie übergeht. Fin eigentlicher prompter Reflex ist nicht auszulösen - wie beim Externus -, während der Sphincter internus und das Rektum auf Reizung durch Bewegen des untersuchenden Fingers mit Verstärkung der tonischen Kontraktion antworten. Doch auch diese träge Reaktion der Darmwand und des Sphincter internus, die weniger einem Rückenmarksreflex als einem "peristaltischen Reflex" entspricht, setzt nach 15 bis 20 Sekunden aus, um einer völligen Erschlaffung Platz zu machen, die so lange andauert, als der untersuchende Finger im Rektum liegt. Erst nachdem man eine Ruhepause von mehreren Minuten eingeschaltet hat, ist wieder eine ordentliche tonische Kontraktion gegen Fingereinführung zu konstatieren.

Nach zehn 'Tagen folgte die Rekonstruktion des Sphincter externus durch Incision in der Narbe, Präparation der Externusstümpfe und Vereinigung derselben beidseitig durch je drei Katgutknopfnähte. Naht der Wunde. Schon nach zwei Tagen stellt man fest, daß der Anus wieder wie beim normalen Tier vollständig geschlossen, der Rektalschleimhautsaum verscliwunden ist. Bei Einführung des untersuchenden Fingers ins Rektum fällt der bedeutend gesteigerte Sphinkterwiderstand auf. Die früher konstatierte Relaxation des Sphincter internus und des untersten Rektalabschnitts nach Ein- 
führung des Fingers bleibt jetzt aus, und da der Sphincter externus wieder gut kontraktionsfähig den Analring umschließt, sind wieder prompte reflektorische Schließkontraktionen des Sphinkterrings in beliebiger Zahl auszulösen, sowohl durch Reizung der Rektalschleimhaut als der perianalen Hautbezirke. Auch wenn der untersuchende Finger mehrere Minuten im Rektum verweilt, tritt eine Erschlaffung des Sphinkterrings und der Rektalwand nicht ein. Wir überzeugten uns wieder durch mehrmalige Nachuntersuchung von der Konstanz und Richtigkeit unserer Beobachtung, und versäumten nicht, um jede Selbsttäuschung auszuschließen, die geschilderten Erscheinungen durch Dritte ebenfalls konstatieren zu lassen. Mit diesem Versuche war somit hinsichtlich des merkwürdigen Abhängigkeitsverhältnisses zwischen Rektum mit Sphincter internus und Sphincter externus die Parallele zwischen den erwähnten klinischen Fällen und dem Versuchstier so weit gegeben, daß man auf experimentellem Wege an ein weiteres Detailstudium der Frage gehen konnte.

Es erwies sich als angezeigt, die weitere Versuchsanordnung etwas zu modifizieren, d. h. nicht bei der einfachen Inspektion und Digitaluntersuchung zu bleiben, sondern den Mechanismus der Sphinkteren an ihrem Verhalten gegenüber flüssigem Rektalinhalt zu studieren. Zu dem Zwecke schien uns die etwas modifizierte Versuchsanordnung von v. Frankl-Hochwart und Fröhlich am geeignetsten. Die Hunde wurden in guter Morphium- ̈̈thernarkose laparotomiert, das Colon pelvinum vorgezogen und nach umschriebener Isolierung vom Mesenterium quer getrennt. Das obere Darmende wurde in den obern Wundwinkel eingenäht, das untere dagegen im untern Wundwinkel fixiert, und die Bauchwunde zwischen beiden Fisteln geschlossen. Durch die untere Darmfistel konnte nun das Rektum jederzeit mittelst eines Schlauchs mit einer Meßbürette verbunden werden, zur Beobachtung des Sphinkterenmechanismus und direkten Messung der Sphinkterschlußkraft, während das Anlegen eines Anus praeternaturalis gestattete, die Tiere event. längere Zeit am Leben zu erhalten, um sie wiederholt und unter verschiedenen Bedingungen (mit und ohne Narkose) zu untersuchen. - Zur Ausschaltung der Willkür bedienten wir uns der Narkose, da es uns ja nur darum zu tun war, Vergleichswerte zu gewinnen. Unter diesen Umständen war auch die Verabreichung von Morphium nicht kontraindiziert - zur Erzielung einer raschen und guten Narkose beinahe unerläßlich - wenn man bei der Beurteilung der Schlußkraft nur in Betracht zog, daß Morphium den Tonus der Analsphinkteren herabsetzt. Unsere Werte sind also 
keine absoluten, sondern nur relative Vergleichswerte. - Quere Markdurchitrennung zur Ansschaltung der Willkür war für unsere Zwecke nicht zu verwenden, weil dadurch das Verhalten der Reflexe ja sehr bedeutend geändert wird, und Kuraresierung konnte ebensowenig verwertet werden, da bekanntlich der Sphincter externus durch Kurare ebenfalls deutlich beeinflußt, wenn auch, sogar durch sehr hohe Dosen nicht vollständig ausgeschaltet wird (von Frankl-Hochwart und A. Fröhlich). Fs besteht also eine gewisse, wenn auch nicht vollständige Immunität dieses Muskels gegenüber Kurare. - Natürlich blieb stets zu berücksichtigen, daß die mechanische Leistung der Sphinkteren durch die Narkose deutlich herabgesetzt wird. Wir narkotisierten die Tiere stets nur so weit, daß sie keine Schmerzempfindung mehr hatten, also ein ruhiges Operieren möglich wurde; dieser Grad der Narkosentiefe wurde sorgfältig unterhalten. Die Reflexe des Sphincter externus waren dabei stets leblaft und kräftig.

Die Untersuchungen am Tier Nr. 2 zeigten zunächst, daß durch den Reiz des ins Rektum einfließenden (körperwarmen) Wassers (Sol. physiol.) und anch durch den Reiz, den jede plötzliche Drucksteigerung durch Frhöhung bzw. Vermehrung der auf den Sphinkteren ruhenden Wassersäule darstellt, die tonische Kontraktion der Analschließmuskeln verstärkt wird. Auch das mit Wasser angefüllte Rektum bewahrt einen gewissen Tonus, der erst durch einen höheren Wasserdruck überwunden wird: es tritt dann erhebliche Dilatation des Mastdarms ein, während die gut kontrahierten Spinkteren noch weiterer Drucksteigerung standhalten. Dabei muß wan sich stets überzeugen, daß der Wasserdruck wirklich von den Sphinkteren, und nicht etwa von dem ad maximum kontrahierten Rektum gehalten wird. - Wir können also bestätigen, daß am Mastdarmende ein permanenter, vom Willen unabhängiger Verschluß besteht, daß somit die Spinkteren einen Tonus im Sinne Heidenhains besitzen. Diese tonische Schlulskraft ist nicht konstant, sondern sie wechselt je nach den Anforderungen, die an die Sphinkteren gestellt werden, innerhalb gewisser Grenzen, die von Tier zu Tier individuelle Schwankungen zeigen. Wir können die Tonusstärke ausdrücken durch die Höhe der von den Sphinkteren gehaltenen Wassersäule, und fanden so bei Versuchstier 2 einen maximalen Wert von $190 \mathrm{~mm}$ Wasser. Bei Übersteigen dieses Druckwertes wird der Sphinkterverschluß durch die Wassersäule gesprengt; doch fließt der Rektalinhalt nicht vollständig ab, sondern nur bis zu einer Höhe von $80-84 \mathrm{~mm}$. Sobald das Flüssigkeitsniveau bis zu diesem Punkte 
gesunken ist, genügt die Schlıßkraft der Sphinkteren wieder, dem weitern Ausfließen des Mastlarminhaltes erfolgreichen Widerstand entgegenzusetzen. Dieser maximale und minimale Druckwert als Ausdruck der tonischen Sphinkterschlußkraft erwiesen sich für ein und dasselbe Tier als konstant. Nach Trennung des Sphincter externus sank die Wassersäule auf Null -- somit beträgt die Schlıßkraft des isolierten Sphincter internus für Flüssigkeit (in Narkose) $=0$. Damit ist auch dargetan, dal3 bezüglich des Sphincter internus von einem elastischen Schluß, der für Flüssigkeiten suffizient wäre, nicht gesprochen werden kann. Dagegen zeigt der Spincter internus bein nichtnarkotisierten Tier wieder einen dentlichen Tonus; sein maximaler Wert schwankte bei melreren Untersuchungen von 70-107 $\mathrm{mm}$, sein minimaler von $30-45 \mathrm{~mm}$. Es ist eben $\mathrm{zu}$ bedenken, dals diese Versuche am nichtnarkotisierten Tiere angestellt werden mußten, wo die Aktion willkürlicher Muskeln (des Beckenbodens und der Bauchwand namentlich) geringe Sclıwankungen bedingen kann. - Eine wesentliche Beobachtung bei diesem Hunde war noch, dals Fingereinführung sofortige Relaxation des Sphincter internus zur Folge hatte. Entsprechend entleerte sich der bis zu einem mittleren Druckwerte gefüllte Enddarm stets vollständig, sobald man einen Finger in den Anus einführte und rasch wieder zurückzog. Diese Frscheinung steht in direktem Gegensatz zu dem später zu schildernden Verhalten bei intaktem Sphinkterring, d. h. bei erhaltenem Externus.

Analog wurde ein weiteres Tier (Nr. 3) untersucht; nur stellte man hier zunächst die Schluljkraft des ganzen Sphinkterrings beim nichtnarkotisierten Tiere fest. Der maximale, durch den Sphincter internus plus externus gehaltene Wasserdruck betrug hier 350 bis $380 \mathrm{~mm}$; entsprechend der erhaltenen Willkür müssen hier die Schwankungen größer sein, was sich namentlich darin zeigte, daß die Entleerung des Rektums sehr verschieden weit ging, wenn einmal der maximale Druckwert, welcher von den Sphinkteren eben noch gehalten werden konnte, überschritten wurde. Das wache Tier hatte natürlich die Möglichkeit, aktiv den Rektalinhalt auszupressen, unter Anstrengung der Bauchwandnushulatur. Meistens ging die Entleerung nur bis zu $230-240 \mathrm{~mm}$, manchmal auch weiter herunter, nie jedoch wurde sie vollständig.

Füllte man bei diesem Tier das Rektum bis zu einem mittleren Druckwert (also bis zu etwa $250 \mathrm{~mm}$ ) und sprengte man dann den Sphinkterverschluls durch Einführung eines Fingers per anum, so spritzte beim Zurückziehen des Fingers nur ganz momentan etwas 
Wasser aus dem Rektum aus; sofort fand wieder ein kräftiger Sphinkterschluß statt. Im Gegensatz hierzu haben wir oben gesehen, daß beim Hunde mit getrenntem Externus Fingereinführung eine vollständige Entleerung des Rektums auslöst. Auch diese Beobachtung stimmt vollkommen mit der klinischen Erfahrung überein. Das narkotisierte Tier zeigte wieder deutlich einen maximalen (reflektorisch gesteigerten) und einen minimalen Tonuswert, entsprechend einem maximalen Druck von $260-285 \mathrm{~mm}$, einem minimalen von 180-190. Diese Schwankungen erwiesen sich abhängig von der Respiration und dem Kontraktionszustand des Rektums, der oft sehr rasch sich verändert. Wichtig scheint uns die Beobachtung, daß auch in Narkose der Hund mit intaktem Sphincter externus nur momentan etwas Wasser ausspritzt, wenn man den Sphinkterverschluß mit dem Finger sprengt. Die Trennung des Sphincter externus hatte auch bei diesem Versuchstier den Effekt, daß der Sphinktertonus auf den Wert 0 absank. Ohne Narkose hielt dieser Internus ${ }^{1}$ ) 85-105 mm (maximal) Wasser; Fingereinführung ins Rektum hatte nachherige vollständige Entleerung des Darms zur Folge.

Bei einem weitern Tier (Nr. 4) ergibt die Messung der Schlußkraft des ganzen Sphinkterrings (wacher Zustand des Versuchstiers) maximale Werte von $400-450 \mathrm{~mm}$, minimale von $260-350$; die Frhaltung der Willkür hat hier also sehr große Schwankungen zur Folge. Sprengung des Sphinkterschlusses bedingt wieder nur momentanes Ausspritzen von Flüssigkeit.

Aus diesen Versuchen geht zur Evidenz hervor, daß nicht nur quantitative, sondern auch qualitative Unterschiede zwischen dem Sphinktermechanismus bei intaktem oder bei getrenntem Sphincter externus bestehen. Mit andern Worten: der Spincter internus agiert verschieden, je nachdem der Externus erhalten oder getrennt ist. Vor allem wird klar, daß beim narkotisierten Tier der äußere Schleißer der wesentliche Träger des Tonus ist, während der Tonus des glatten Sphinkters durch die einverleibten Narkotika scheinbar auf den Nullwert reduziert wird. Der Sphincter internus allein vermag dem völligen Ausfließen des Rektalinhalts keinen Widerstand entgegenzusetzen, sobald einmal der Analschluß durch Einführen eines Fingers ins Rektum gesprengt ist, während bei intaktem Externus nur momentan während des Zurückziehens des Fingers etwas Wasser ausfließt, worauf sofort wieder zuverlässiger Anal-

1) Gemeinsam mit dem Rektum (s. weiter unten). 
schluß erfolgt. Von prinzipieller Wichtigkeit scheint uns auch die Tatsache, daß nur für den Sphincter externus eine wesentliche reflektorische Steigerung der tonischen Schlußkraft nachweisbar ist; diese den jeweiligen Anforderungen proportionale Steigerung konstatiert man auch am narkotisierten Tier, bei dem ïberhaupt kein Internustonus mehr vorbanden ist, sobald der Externus getrennt wird. Dagegen hat der Sphincter internus auch beim narkotisierten 'Tier zweifellos einen Anteil am tonischen Analschluß, solange der Externus funktionsfähig ist. Den Nachweis für diese Behauptung werden wir weiter unten erbringen.

Nach unsern Messungen beträgt der Anteil des Sphincter internus am tonischen Analschluß beim nichtnarkotisierten Hunde 35-40 Proz., derjenige des Sphincter externus entsprechend 60 bis 65 Proz.

Für diese Berechnungen waren natürlich die Mittelwerte maßgebend. Daß überhaupt im Experiment nicht direkt ein mittlerer Wert für die Tonusstärke abgelesen werden kann, beruht auf der Besonderheit des Sphinktermechanismns. Schon die geringste Menge ins Rektum einfließenden Wassers löst sofort eine inspektorisch konstatierbare Verstärkung der Sphinkterkontraktion aus. Wir können nun zunächst nur feststellen, daß mit dem Steigen des Wasserdrucks auch der Sphinktertonus in zweckentsprechender Weise stärker wird, und können auch den Druck bestimmen, durch welchen der tonische Sphinkterschluß gesprengt wird. Durch einen gewissen Wasserdruck wird also die mechanische Leistung der Analschließmuskeln überwunden, der Sphinkter wird gedehnt, und das Wasser fließt nun so lange aus, bis die Sphinkteren Zeit gefunden haben, sich wieder ordentlich zu kontrahieren. Das Niveau, bis zu welchem die Wassersäule sinkt, gibt uns den Wert für die minimale meßbare Tonusstärke. Wir glauben, daß auch bei leerem Rektum die Sphinkteren einen gewissen Tonus besitzen, da sonst der Anus offen stehen müßte. (Merkwürdigerweise finden sich in der physiologischen Literatur Angaben, die das Vorhandensein eines Sphinktertonus im Ruhezustand bestreiten; vgl. Landois, Lehrb. der Phys.). Doch ist diese Tonusstärke nicht melbar, weil jede Manipulation zu Meßzwecken einen lokalen Reiz bedingt und sofort zu reflektorischer Verstärkung des Tonus führt. Das war auch der Grund, warum v. Frankl-Hochwart und Fröhlich die Leistung der Analsphinkteren an der Unterbrechung eines durchfließenden Wasserstromes gemessen haben, und warum die Messung auf pneumatischem Wege unter Einführung eines kleinen Ballons in die 
Pars perinealis des Rektums keine zutreffenden Resultate zu geben vermag. So müssen wir uns mit diesen relativen Werten begnügen. Über dic Leistung der Sphinkteren, speziell des Sphincter internus, bei Reizung der versorgenden Nerven direkt und anf reflektorischem Wege, haben v. Frankl-Hochwart und A. Fröhlich ausgiebige Untersuchungen angestellt. Für unsere Zwecke kam es nur darauf an, das Verhalten der Sphinkteren, ohne jede weitere künstliche Beeinflussung, gegenüber flüssigem Rektalinhalt zu prüfen. Die auf Körpertemperatur erwärmte phys. Kochsalzlösung stellt sicher keinen übermäßigen Reiz dar. - Zum mindesten erhält man so brauchbare Vergleichswerte.

Auf den ersten Blick scheint die Tatsache, đaß der Sphincter internus allein beim nichtnarkotisierten Tier auch eine gewisse, meßbare Wassersäıle zu tragen vermag, der klinischen Beobachtung zu widersprechen. Man würde erwarten, daß entsprechend der Inkontinenz gegen dünnen Kot die Tiere mit getrenntem Sphincter externus auch gar keine Flüssigkeit zu halten vermöchten. Hiergegen ist einzuwenden, daß es sich in diesen Fällen nicht um eine eigentliche Leistung des Sphincter internus, sondern un eine Leistung des gesamten Rektums inklusive Sphincter internus handelt. Jenn man kann sich in diesen Fällen leicht überzengen, daß es hier nicht zu einer Dehnung des Rektums bis zur Pars perinealis kommt, so daß nur der Sphinkter den Abschlnß besorgt, sondern daß das ganze Rektum kontrahiert ist und den Abschluß mit besorgt. Da ein kräftiger Sphinkterschluß nach Trennung des Externus nicht erfolgt, kann das Rektum von der Meßbürette her auch nicht bis zu eintretender Dilatation gefüllt werden, und es bedarf deshalb in diesen Fällen nur geringer Wassermengen, um in der Bürette eine meßbare Wassersäule zu bekommen $(10-20 \mathrm{cc})$; ist dagegen der Sphincter externus intakt, so bedarf es wenigstens 100-150 cc Wasser - je nach Größe des Tieres -, bis man in der Meßbürette ein ständiges Flüssigkeitsniveau zu Gesicht bekommt, weil in diesen Fällen, wo ein kräftiger Analschluß stattfindet, zunächst das Rektum ad maximum dilatiert wird, und, erst nachdem das dilatierte Rektum angefüllt ist, nach weiterem Zugießen von Wasser das Niveau in der Meßbürette zu steigen beginnt. Den Ansatz des Schlauches bis vor den Sphinkter vorzuschieben, ging nicht an, weil dadurch eben ein unphysiologischer Reiz auf die Mucosa ausgeübt worden wäre. Es ist leicht ersichtlich, daß durch das leicht kontrahierte Rektum, in welchem die Falten der Mucosa sich berühren, schon allein infolge des Reibungswiderstandes eine niedrige Wassersäule ge- 
halten werden kann. Das Wesentliche und Entscheidende bleibt, daß bei narkotisierten Tieren, wo auch der Tonus der Rektalwand herabgesetzt ist, der isolierte Sphincter internus keinen meßbaren Wasserdruck zu halten vermag, und daß auch die wachen Tiere mit ihrem Sphincter internus keinen flüssigen Rektalinhalt zurückzuhalten vermögen, sobald einmal die leichte tonische Sphinkterkontraktion durch Einführung eines Fingers überwunden ist. Mit andern Worten: Nach Trennung des Sphincter externus löst Fingereinführung einen Entleerungsreflex aus, weil der Splincter internus wie das übrige Rektum den Gesetzen der Peristaltik gehorcht, während, solange der Externus noch funktionsfühig ist, stets prompter Abschluß des Rektums erfolgt. Schon aus diesen Versuchen geht also hervor, daß der äußere Schließmuskel der wesentliche "Sphinkter" ist, während der innere Schließmuskel nur in untergeordneter Weise am Analschluß beteiligt ist.

Die weitern Versuche gingen nun dahin, nicht den ganzen Sphincter exteruus anf einmal, sondern nur sukzessive zu trennen, um zu sehen, ob auch im Experimente eine kleine Partie des äußern Schließmuskels genüge, den glatten Sphinkter in der beschriebenen charakteristischen Weise zu beeinflussen. Zu diesen Untersuchungen dienten die Tiere Nr. 8, 9 and 10. Am Versuchstier 8 wurde die eine Seite des Splincter externus in drei Partien durchschnitten. Natürlich trennte man mit Rücksicht auf die Art der Innervation zunächst die anale, dann die mittlere und erst zuletzt die oralste Portion. Auffälligerweise hielt der Hund noch etwas mehr als ein Drittel der gesamten, vom intakten Sphinkterring getragenen Wassersäule. Die genauere Beobachtung zeigte aber, daß der Schluß dabei nicht mehr durch eine reine "Sphinkterwirkung" zllstande kam, sondern dadurch, dals das Ende des Rektums durch die intakte Hälfte des Externus seitlich zusammengedrückt wurde. Trennung dieser Hälfte hob die Schlußkraft des Analrings sofort vollständig auf.

Deshalb wurde bei den Versuchstieren Nr. 9 und 10 das Vorgehen dahin abgeändert, daß der Externus in drei Partien beidseitig getrennt wurde, damit nicht zuletzt noch eine ganze intakte Hälfte des Muskels stehen bleibe. Dabei zeigt sich nun auffälligerweise, daß Trennung des analen Drittels den geringsten Effekt hat, indem der maximale Tonuswert nur um ca. $1 / 5$ sinkt; und doch ist gerade die aborale Partie des Sphincter externus diejenige, welche den Enddarm zirkulär umschließt und also den vollständigsten „Sphinktereffekt" haben sollte. Bei 'Trennung des mittleren Drittels des Ex- 
ternus sinkt die tonische Schlußkraft am Anus um weitere $\%$. Da, wie wir früher gesehen haben, der isolierte Sphincter internus beim narkotisierten Tier keine meßbare tonische Schlnßkraft mehr besitzt, wäre anzunehmen, daß dem schwächsten, oralen Drittel des Externus jedenfalls nicht mehr als der proportionale Anteil an der gesamten Sphinkterwirkung zukommen sollte. In Wirklichkeit beträgt aber dieser Anteil $2 / 5$ bei Tier Nr. 9, bei Tier Nr. 10 sogar noch etwas mehr, nämlich 43,3 Proz. - Sobald wir auf der einen Seite das stehen gebliebene orale Drittel des Externus durchtrennen, fällt die Wassersäıle sofort auf Niveau 0. Wir können diese Erscheinung nur so erklären, daß mit dem oralen Drittel des Externus der Sphincter internus noch mitagiert, während er selbständig bei narkotisiertem 'Tier' einen kräftigen Analschluß nicht herzustellen verInag. So erklärt sich auch, wartum der aboralen Portion des Sphincter externus eine geringere Wirkung zukommt, als dem mittleren Drittel (1/5 gegen ca. $2 / 5$ ); denn das aborale Drittel, welches den Sphincter internus nach unten überragt, hat keinerlei mechanischen Einfluß auf den Sphincter internus, da letzterer erst weiter oben, d. h. etwa am Übergang vom aboralen zum mittleren Drittel des Externus, beginnt.

Als unzweifelhaftes Resultat geht deshalb unseres Erachtens aus diesen Versuchen hervor, daß der Sphincter externus die Aktion des glatten innern Sphinkter in sehr deutlicher Weise beeinflußt, indem sich der Internus bei narkotisiertem Tier so lange am tonischen $A$ nalschluB beteiligt, als er noch durch eine funktionsfähige Partie des quergestreiften Sphinkters dazu angeregt wird. Obschon wir die Trennung des Externus stets ganz gleichmäßig unter genauer Isolierung je eines Drittels vorgenommen haben, sank die Schlußkraft des Sphinkterrings nicht proportional, sondern das schwache orale Drittel hielt noch beinahe die Hälfte der vom intakten Splinkterring getragenen Wassersäule - aus dem einfachen Grunde, weil zu der Komponente des oralen Fxternusdrittels sich noch die Komponente des Internus hinzuaddiert. Allein vermag der Internus (in Narkose) nichts zu halten, also verdankt er seine Wirksamkeit in Narkose der Beeinflussung durch den sich kontrahierenden Sphincter externus. - Natürlich wurde nicht versäumt, vor der Durchtrennung des stehengebliebenen oralen Drittels des Sphincter externus jeweilen noch durch Digitaluntersuchung das Verhalten des Analrings festzustellen, und dabei zeigte sich, wie zu erwarten stand, daß der Internus sich gut um den Finger schloß, daß aber 
Relaxation eintrat, sobald auf einer Seite die Fasern des äußern Schließers getrennt wurden. -

Bezüglich der Frage der "mechanischen“ Beeinflussung des Sphincter internus durch den Sphincter externus bleibt nun noch übrig, die Beobachtungen zu besprechen, die wir am Versuchstier Nr. 6 machten. Bei diesem Hund wurde analog wie im allerersten Experiment der Sphincter externus beidseitig getrennt; doch legten wir hier besonderen Wert darauf, auch den M. coccygens und M. levator ani, die gemäß ihres anatomischen Verlaufs beim Hunde den Enddarm komprimieren und so zum Verschlusse beitragen können, ebenfalls zu durchschneiden. Wir hatten bei andern Versuchstieren die Beobachtung gemacht, daß der Externus nicht stets scharf nach oben hin abgegrenzt ist, sondern daß manchmal isolierte quergestreifte Fasern, die im Experiment leicht an ilrer prompten reflektorischen Kontraktion erkannt werden, sich noch $2-3 \mathrm{~cm}$ oberhalb des eigentlichen Sphinkterendes um den Enddarm herumziehen. Es war natürlich wichtig, auch diese Fasern sorgfältig zu trennen, um jede Fehlerquelle auszuschalten. - Bei diesem so operierten Tier nun, das wir während längerer Zeit beobachteten, fanden sich die bei $\mathrm{Nr}$. 1 gemachten Erfahrungen vollkommen bestätigt. Während vor der Muskeltrennung jede Reizung der Mastdarmschleimhaut durch den untersuchenden Finger eine prompte Kontraktion des Analrings ausgelöst hatte, und die Sphinkteren danernd tonisch kontrahiert blieben, zeigte sich nach der Operation, daß nur zu Beginn einer digitalen Rektaluntersuchung einige träge Zusammenziehungen des Sphincter internus erfolgten, die jedoch rasch absoluter Atonie wichen. Besonders interessant war, daß dieser Hund, wenn man ihn im Stehen untersuchte, sofort "Hockstellung" einnahm, den Schweif hob und energische Defäkationsanstrengungen machte, die sich namentlich in heftiger Anstrengung der Banchpresse äußerten; meistens wurde dabei die Rektalmucosa aus dem After hervorgepreßt; schon ganz leichte Fingereinführung gen ügte, um diesen typischen, zusammengesetzten Defäkationsreflex auszulösen, während vor der I)urchtrennung des Sphincter externus - wie mehrmals an demselben Tier konstatiert worden war - Fingereinführung stets eine kräftige Zusammenziehung der Sphinkteren und des untersten Rektalabschnitts zur Folge geh abt hatte. Zndem hatte derHund jede Digitaluntersuchung des Rektums durch krampfhaftes Anpressen des Schweifes zu verhindern gesucht. Wie durch Fingereinführung, so wurde auch durch jedes Tiefertreten von Kot in den Mastdarm sofort der Entleerungs- 
mechanismus ausgelöst, da wir bei mehrmaligen Untersuchungen das Rektum des Versuchtiers stets leer fanden. - Entsprechend erklärt sich die Inkontinenz in den anfangs beschriebenen klinischen Fällen.

Nachdem wir den experimentellen Nachweis erbracht haben, daß der Sphincter externus der eigentliche Erhalter des Analschlısses ist, und $\mathrm{da}$ der Sphincter internus wesentlich nur unter dem Einfluß des Sphincter externus, d. h. von diesem dazu angeregt am Abschluß des Rektums, im besondern an der Zurückhaltung der Fäkalmassen mitzuwirken vermag, bleibt nur noch übrig, zu diskutieren, wie diese funktionelle Abhängigkeit zu erklären ist, und eine zusammenfassende Darstellung des Mechanismus der Rektalsphinkteren zu geben, unter Berücksichtigung der neuen, vorstehend diskutierten und bewiesenen Tatsache. Zu dem Zwecke müssen wir zunächst kurz auf die Physiologie der Darmbewegung und der Kotentleerung eingehen; wir halten uns dabei wesentlich an die neuere physiologische Literatur; soweit wir selbst im Laufe der Untersuchungen Experimente über die Rektal- und Sphinktereninnervation angestellt haben, werden wir die bezüglichen Ergebnisse an entsprechender Stelle anführen und besprechen. -

Am vollständigsten sind unsere Kenntnisse über die Bewegungen des Dünndarms, die wir in erster Linie in den Kreis unserer Besprechung ziehen müssen, um die wesentlichen Gesetze der Bewegung glatter Darmuuskulatur kennen zu lemen.

Mit seiner Längs- und Ringmuskelschicht führt der Dünndarm peristaltische, und rhythmische Pendelbewegungen aus. Die peristaltische Bewegung erfolgt nach Bayliß und Starling in der Norm auf mechanischen Reiz hin, nämlich auf Berührung der $\mathrm{Mu}$ cosa durch feste Körper. Mit Rücksicht auf die uns hier speziell interessierende Frage ist besonders wichtig, daß auch lokalisierte starke mechanische, chemische oder elektrische Reizung der Außenfläche des Darms genügt zur Auslösung des peristaltischen Reflexes, also ganz allgemein zur Anslösung von Kontraktionen der Darmmuskulatur. Die peristaltische Bewegung wird dadurch charakterisiert, daß magenwärts vom gereizten Punkt Bewegungssteigerung, d. h. Kontraktion mit Verengerung des I)armlumens eintritt, unter gleichzeitiger Henmung, also Erschlaffung der analwärts gelegenen Partien. Dadurch wird der Kotballen afterwärts bewegt, da er an jeder Stelle wieder den gleichen Reiz auslöst (Magnus). Es ist klar, daß die Ringmuskulatur den wesentlichen Anteil an der Peristaltik hat; die Längsmuskulatur wirkt synergetisch oder antagonistisch mit. Da der peristaltische Reflex auch 
am isolierten Darm beobachtet wird, liegt sein Zentrum in der Darmwand selbst. Die peristaltische Kontraktion und die Ausbreitung der Wirkung lokaler Kontraktion sind demnach abhängig von den lokalen Nervenzentren im Darm, den sog. Repräsentanten. Der Reflex ist im Zentrum fest vorgebildet, d. h. er kann nur vom Magen nach dem After zu laufen, da Ellinger und Prutz durch Gegenschaltung isolierter, aber mit ihrem Mesenterium in Verbindung gelassener 1)ünndarmstärke bewiesen haben, daß eine Antiperistaltik im Dünndarm nicht existiert. Die Pendelbew egungen bestehen in rhythmischen Kontraktionen und Erschlaffungen der Ringmuskulatur, die mit rhythmischer Verkürzung und Wiederverlängernng der Längsmuskelschicht alternieren. Dadurch entstehen die rhythmischen Segmentationen des Darms (Cannon). Das Zentrum für die Pendelbewegungen wie für die peristaltischen Bewegungen ist der Auerbachsche Plexus. In den im Darm gelegenen Reflexbogen greifen Fasern aus dem Zentralnervensystem ein, die teils im Vagus, teils im Splanchnicus verlaufen. Nach Bayliß, Starling und Bunch führt der Splanchnicus ausschließlich hemmende, der Vagus erregende und hemmende Fasern. Gewöhnlich überwiegt die Splanchnicuswirkung. Doch hat das in der Darmwand gelegene nervöse System eine weitgehende Autonomie, indem Magnus und Langley $\tilde{\mathbf{5}}-14$ Tage nach Durchschneidung aller postganglionären Fasern sämtliche Reflexe am Darm in beinahe unverminderter Stärke und normaler Form beobachtet haben. - Der Vollständigkeit halber sei noch erwähnt, daß im Dünndarm auch ein Transport von Flüssigkeiten und in ihnen suspendierter, kleinster, fester 'Teilchen nach aufwärts stattfindet, und zwar durch die Pendelbewegungen. Diese durch Grützner am Tier gemachten Frhebungen wurden durch Hemmeter am Menschen bestätigt. Ü̉ber die Funktion der vom Meißnerschen Plexus beherrschten Muscularis mucosa sind die Arbeiten von Exner (s. Liter. Verzeichnis) nachzusehen. - Der Dickdarm, dessen Bewegung namentlich von Starling und Bayliß, Elliot, Barclay-Smith, Cannon, Langley und Magnus studiert worden sind, zeigt Pendelbewegung und Peristaltik, die den gleichen Gesetzen unterworfen sind, wie die analogen Bewegungen des Dünndarms, und ebenfalls von autonomen, in der Darmwand selbst gelegenen Nervenzentren dirigiert werden. Beim Hund haben die Splanchnici eine schwach hemmende, die Nerven des Beckenplexus eine bewegungsverstärkende Wirkung. Weiterhin beobachtet man am Dickdarm eine Antiperistaltik, die sich auf das Cöcum und das proximale Colon beschränkt; sie beginnt, sobald 
sich der Dickdarm vom Dünndarm her mit Inhalt füllt, und dient der weitern Durchknetung und Durchmischung, und indirekt wohl auch der Eindickung des Speisebreis bzw. Kots. Als vierte Bewegungsform sieht man am Dickdarm auf Reizung der Nerven des Beckenplexus (beim Hund aus dem 2. und 3. Sacralnerven stammend) eine vorübergehende Hemmung (Bayliß und Starling) und dann eine gleichmäßige tonische Kontraktion der distalen Hälfte des Colons (Elliot und Barclay-Smith). Nach Bayli B und Starling ist diese Bewegungsform wohl unphysiologisch, da man auch beim Ösophagus durch Reizung des Vagus eine gemeinsame Kontraktion hervorrufen könne, während das Organ normalerweise nur Peristaltik zeige.

Bedeutend komplizierter sind die Verhältnisse hinsichtlich der Bewegung des Rektums und des Sphinkterenmechanismus; "genauer untersucht sind nur die Innervation und die Tätigkeit der Sphinkteren" (Cohnheim, in Nagels Handbuch der Physiologie). Bezïglich der Innervation des Rektums und der Sphinkteren folgen wir im wesentlichen der Darstellung von v. Frankl-Hochwart und Fröhlich, die sich zum Teil auf die Untersuchungen von Langley und Anderson stützt.

Der Sphincter externus wird beim Menschen versorgt durch die Ni. haemorrhoidales inferiores, beim Hunde vom N. haemorrhoidalis medius, einem Aste des N. pudendus internus. Für die Innervation des Rektums und des glatten Sphincter internus kommen (beim Hund) eine obere oder Lumbalnervengruppe und eine untere, sacrale Nervengruppe in Betracht. Der wesentliche Nerv der obern Gruppe ist der Nervus hypogastricus, beim Hunde paarig angelegt, ausgehend von dem auf der Arteria mesenterica inferior reitenden Ganglion mesentericum inferius. $\mathrm{Zu}$ diesem Ganglion kommen Fasern vom 3. und 4. Ganglion des Lendenteils des Sympathicusgrenzstranges, sowie ein 3. Nervenfaden, der zwischen 3 . und 4. Ganglion vom Grenzstrang abgeht und sich mit dem vom 4. Ganglion kommenden Ast vereinigt; links kommt eine Faser vom 2., eine vom 3. Grenzstrangganglion, und eine 3. Faser, die etwas oberhalb des 4. Ganglions vom Grenzstrang abgeht. Daneben bestehen rechts noch indirekte Verbindungen zwischen Ganglion mesentericum inferius und 1. und 3. lumbalen Grenzstrangganglion, auf dem Wege des Nervus aorticus. Aus dem Ganglion mesent. inf. entspringen mindestens vier lumbare Colonnerven, und rechts sowie links je ein N. hypogastricus, der seitlich vom Rektum ins Becken hinuntersteigt und dort Verbindungen mit den sacralen Nerven eingeht (Plexus 
hypogastricus), bevor er an den Enddarm und an die übrigen Beckenorgane herantritt. Die untere - sacrale - Nervengruppe entspringt in der Regel aus den 3 Sacralwurzeln, der wichtigste Nervenstrang unter ihnen ist der Nervus erigens (Eckhard) oder N. pelvicus (Langley). Der N. pelvicus stammt wesentlich aus der 2. Sacralwurzel, mit Verbindungen von der 1. und 3. Wurzel her. Die $\mathrm{N}$. pelvici sive erigentes verlaufen seitlich am Becken zum Plexus hypogastricus, in den von oben her die Nn. hypogastrici einstrahlen. Aus dem Plexus hypogastricus ziehen zahlreiche Verbindungszüge zur Blase, Prostata, Urethra und namentlich in den Endteil des Darms. Andere Nervenzweige aus dem Plexus bypogastricus ziehen oralwärts zum Rektum. Kinige spärliche Nervenfäden gehen auch vom Endteil des Sympathicusgrenzstrangs direkt zum Mastdarm.

Die Innervationsverhältnisse des Mastdarms beim Menschen sind relativ einfach zu skizzieren, da wir den Faserverlauf nicht annähernd so genau kennen, wie beim Tier. Das ganze Rektum inklusive Sphincter internus wird nur von Fasern des sympathischen oder autonomen Nervensystems versorgt, die zum größten Teil aus dem Plexus haemorrhoidalis, zum kleinern Teil aus dem Plexus mesentericus inferior stammen. Abgesehen von den Verbindungen mit dem Lumbal- und Sacralsympathicus bestehen Beziehungen zum Plexus ischiadicus und Plexus pudendus, so daß die Verhältnisse wohl ähnlich liegen mögen, wie beim Tier. Doch ist die separate Präparation eines dem Nervus erigens sive pelvicus entsprechenden Faserzuges beim Menschen vorderhand noch ein Desiderat (Waldeyer). - Die äußere Haut des Afters und der Sphincter ani externus werden durch die Nn. haemorrhoidales inferiores, aus dem N. pudendus communis, versorgt. -

Was nun die Wirkung der erwähnten Nerven betrifft, so führen die Frigentes konstringierende Fasern für das Rektum und den Sphincter internus (nach v. Frankl-Hochwart und A. Fröhlich) die Hypogastrici wesentlich dilatierende Fasern. Doch ist im Experiment die dilatierende Wirkung der Hypogastrici nur nach vorheriger Trennung der Erigentes zu erhalten. Es ist auch möglich, von sensiblen Bahnen - Ischiadicus - aus reflektorisch Konstriktion und Dilatation anf dem Wege der Erigentes bzw. der Hypogastrici zu erhalten. Die Konstriktion ist das weitaus Überwiegende. - Weiter wiesen v. Frankl-Hochwart und A. Fröhlich nach, daß sowohl im Erigens wie im Hypogastricus zentripetalleitende Fasern vorkommen, welche genügen, um auf dem 
Wege des spinalen Reflexbogens den Sphincter internus zur Kontraktion oder zur Dilatation anzuregen. Die Resultate Fellners, welcher angibt, daß beim Hunde Reizung der Krigentes Kontraktion der Längs- und gleichzeitige Hemmung der Ringmuskulatur des Rektums hervorruft, während periphere Reizung der Hypogastrici Kontraktion der Ring- und Erschlaffung der I ängsmuskelschicht verursache, dürften durch die Errgebnisse netterer Untersuchungen überholt sein, da es nach Ansicht Starlings (vgl. Asher und Spiro, Ergebnisse der Physiologie, 1902, Bd. 2) „höchste Zeit ist, daß die Lehre von der gekreuzten Innervation der Darmmuskulatur aus der modernen Physiologie verschwinde". - Nach Langley und Anderson erzeugte Hypogastricusreizung Konstriktion des Sphincter internus. - Soweit wir uns in Laufe unserer Untersuchungen mit der Frage der Sphinktereninnervation beschäftigten, müssen wir die Resultate v. Frankl-Hochwarts und Fröhlichs bestätigen. Wir trennten bei Versuchstier Nr. 7 zunächst am narkotisierten Tier die Hypogastrici, und fanden dabei eine deutliche Steigerung des Tonusdruckwertes, zum Beweis, daß die Hypogastrici dilatierende, oder kontraktionshemmende Fasern führen. Durchschneidung der Erigentes hatte - bei erhaltenem Sphincter externus - eine Senkung des Tonuswertes um ${ }^{1 / . j}$ zur Folge, weil eben der tonisierende Finfluß der Erigentes in Wegfall kam. Im gleichen Sinne spricht eine Beobachtung bei Tier Nr. 8, wo die Trennung der Erigentes nach Durchschneidung des Sphincter externus völliges Schwinden des Internustonus zur Folge hatte, so daß der vorher noch leicht geschlossene Anus jetzt klafite. Bei 'Tier Nr. 9 löste Durchreißen der Hypogastrici reflektorisch intensive Kontraktion des Sphincter internus und des stehengebliebenen oralen Externusdrittels aus. Diese wenigen im Nebenexperimente gemachten Beobachtungen sprechen jedenfalls für die Richtigkeit der von v. Frankl-Hochwart und Fröhlich gemachten Erhebungen.

Die ersten nervösen "Zentren" für die Sphinkteren wie für die Rektalwandmuskulatur liegen in ihrer Substanz selbst, da sich ihr Tonus nach Entfernung des Rückenmarks (Goltz und Ewald, v. Frankl-Hocliwart und Fröhlich, L. R. Müller) und auch nach Entfernung der sympathischen Ganglien wiederherstellt. Dabei verhält sich der Sphincter internus wie die übrige glatte Muskulatur des Darms. Der quergestreifte Sphincter externus, der nach Goltz und Fwald sowie nach Arloing und Chantre nach Lostrennung vom Rückenmark nur ganz geringe Degenerationszeichen darbieten soll und seinen Tonus ebenfalls nicht dauernd verliert, 
nimmt physiologisch eine Stellung ein, die ihn eher der glatten Muskulatur nähert: er gab nach Rückenmarksexstirpation keine Entartungsreaktion, zeigte, wie erwähnt, mikroskopisch kaum Zeichen von Degeneration (geringe Kernanhäufung und Vermehrung des interfibrillären Bindegewebes); die Zuckungkurve des Externus ist bei indirekter Reizung nicht die klassische Kurve des Skelettmuskels, wohl aber wird diese klassische Kurve bei direkter Reizung des Muskels erhalten; der Reizeffekt stellt sich langsamer ein und verschwindet anch langsamer als beim Skelettmuskel; der äußere Schließer gerät auch durch eine geringere Anzahl von Induktionsschlägen in Tetanus. Alle diese Verhältnisse sprechen dafür, daß der Externus in seiner Substanz Zentren trägt, was auch aus der teilweisen Immunität des Muskels gegenüber Curare hervorgeht, sowie auch daraus, daß auf einen lokalisierten, elektrischen oder mechanischen Reiz sich stets der ganze Muskel kontrahiert. - Wir müssen allerdings bemerken, daß nach unseren Beobachtungen makroskopisch eine gewisse, deutliche Degeneration des Sphincter externus nach Lostrennung vom Rückenmark zweifellos eintritt. Doch ist dieselbe relativ unbedeutend und manifestiert sich, wie wir an Präparaten von Hund Nr. 5, die Herr Privatdozent Dr. W egelin anzufertigen die Güte hatte, feststellen konnten, wesentlich in einem deutlichen Schmälerwerden der Muskelfasernn, während eine direkte Degeneration nicht ersichtlich ist. So fehlt auch die Kernanhäufung, die man beim degenerierten Skelettmuskel konstatiert. - Das widerspricht aber nicht der durch alle übrigen Momente gestïtzten Annahme, daß auch der Sphincter externus lokale Nervenzentren besitzt.

Die Verbindung dieser, als Repräsentanten bezeichneten lokalen Zentren mit sympathischen Ganglien und mit dem Rückenmark wird, wie wir gesehen haben, wesentlich durch die Hypogastrici (via Sympathicus im engern Sinne) sowie durch die Erigentes (via Sacralwurzeln; sacrales autonomes System) hergestellt. Wir sehen dabei ab von den spärlichen, vom untersten Ende des Grenzstrangs zum Rektum ziehenden Fasern. Für den Sphincter externus geht die motorische Bahn durch den N. haemorrhoidalis. Der Vollständigkeit halber müssen wir noch anführen, daß sich nach den Untersuchungen von Pal (Wiener klin. Wochenschr. 1896/97) auch vom Vagus und Splanchnicus her Bewegungserscheinungen am Rektum und Sphincter internus auslösen lassen; allerdings verlaufen die Splanchnicusfasern für diese Impulse durch das Lumbalmark und einen Teil des Sacralmarks, welches sie auf den Bahnen des N. erigens wieder verlassen. Im Rückenmark soll nach älterer Dentsche Zeitsehrift f. Chirurgie, 101. Bd. 
Anschauung ein Defäkationszentrum sich finden (Centrum genitospinale, Budge; ano-spinale, Masius), welches in die Gegend des 3. und 4. Sacralsegmentes verlegt wird. Nach L. R. Müllers klinischen Beobachtungen stehen beim Menschen sowohl das 2. und 5. Sacralsegment wie das 1. Coccygealsegment in Beziehung zum Sphinkterreflex; nach Langley müssen außerdem Beziehungen des Defäkationsmechanismus zum 2. und 3. Lumbalsegment, vorhanden sein. Nach Kocher befinden sich die motorischen Zentren für den Anus (Sphinkter) im untersten Teil des Conus medullaris, im Bereiche des 4. Sacralsegments, während die sensiblen Fasern für das Rektum etwas höher oben einmünden (vgl. Kocher, Die Läsionen des Rückenmarks bei Verletzungen der Wirbelsäule. Mitteil. aus den Grenzgebieten). Die Frage der Zentren selbst werden wir weiter unten noch kurz diskutieren.

Über den Verlauf der Bahnen aufwärts zum Gehirn haben wir keine sichern Aufschlüsse; wir wissen nur, daß die Fasern für Blase und Rektum beidseitig angelegt sind, so daß Halbseitenläsionen keine Blasen- und Mastdarmstörungen zur Folge haben (vgl. Kocher, loc. cit., S. 533), und daß die betreffenden Fasern entweder nicht in den Pyramidenbahnen verlaufen, oder weniger leicht lädierbar sind als diese, wie aus Beobachtungen an partiellen Querläsionen hervorgeht (vgl. Kocher, loc. cit., S. 576).

Das „Centrum anale“ in der Hirnrinde liegt nach übereinstimmenden Angaben vieler Autoren (Bechterew, Ducceschi, Merzbacher, v. Frankl-Hochwart und Fröhlich) an der Außenseite des Gehirns, etwas nach hinten vom Sulcus cruciatus, ca. $1 \mathrm{~cm}$ unterhalb der Mantelkante, beim anthropoiden Affen nach Sherrington ganz oben im Gebiet der vorderen Zentralwindung, in nächster Nachbarschaft der Beinzentren.

Wieweit nun der Dickdarm an den Defäkationsvorgängen beteiligt ist, wissen wir nicht genau. v. Frankl-Hochwart und Fröhlich haben am Hunde nachgewiesen, daß durch eine peristaltische Kontraktion des unteren Dickdarms in der Regel eine Erschlaffung der Analsphinkteren hervorgerufen wird, die beiden Vorgänge also miteinander verknüpft sind ${ }^{1}$ ). Auch beim Menschen ist über die physiologische Tätigkeit des unteren Dickdarmabschnitts wenig bekannt. Die Ansammlung von Kot scheint sich normalerweise nicht im S. romanum, sondern in der sogenannten Ampulle,

1) Vgl. hierzu die Untersuchungen von Kronecker und Melzer Über (las Verhalten der Kardia beim Schluckakt. 
dem untern horizontalen Mastdarmstück, zu machen, welches nach Waldeyer meistens mit Kot gefüllt ist, während die unmittelbar höhere Darmpartie sowie die Pars perinealis recti meist leer sind. Jedenfalls aber ist zur normalen Defäkation die motorische Integrität des unteren Dickdarms und des ganzen komplizierten Innervationsapparates des Rektums und der Analsphinkteren notwendig, und zwar des Innervationsbogens sowohl in seinem motorischen wie in seinem sensiblen Teil. Merzbacher hat gezeigt, daß Durchschneidung der hinteren Wurzeln des Sacralmarks wirkt wie Rückenmarksexstirpation, d. h. daß von der insensiblen Darmschleimhaut die Defäkationsbewegungen nicht mehr ausgelöst werden, und der Sphinktertonus zunächst schwindet. - Unterbrechung der Leitung hat also zur Folge, daß die Kotentleerung unwillkürlich und ohne daß sie gefühlt wird, vor sich geht. Flüssiger Kot läuft einfach ab, fester Kot sammelt sich im Rektum an - Obstipation! und fällt nur gelegentlich, von den nachdrängenden Massen geschoben, aus dem Anus heraus, ohne daß die Hunde dabei „Hockstellung" einnehmen. Der Tonus der Sphinkteren nimmt aber nach einiger Zeit wieder zu, nachdem er ganz oder teilweise herabgesetzt war, nnd die Selbständigkeit der lokalen, im Muskel gelegenen Zentren manifestiert sich dadurch, daß die Kotentleerung wieder "in ziemlich regelnäßigen Intervallen erfolgt". Natürlich werden die Tiere nicht eigentlich wieder kontinent. Goltz hat bei seinen Rückenmarksdurchschneidungen und Rückenmarksexstirpationen die Erfahrung gemacht, daß die Wiederherstellung des Sphinkterentonus und der "geregelten" Defäkation sich nach den Exstirpationen zwar langsamer, aber doch ebenso "vollständig" machte. In neuerer Zeit behauptete namentlich L. R. Müller, daß Querschnittsläsion oberhalb des Sacralmarks die gleichen Blasen- und Mastdarmstörungen mache, wie Exstirpation des Sacralmarks. Die allgemeine Annahme, daß sich Mastdarm und Blase ganz anders verhalten, wenn die Querschnittsläsion oberhalb der spinalen "Zentren" als wenn sie im Bereiche derselben sich lokalisiert, daß also in ersten Falle Retention, im zweiten Falle echte Inkontinenz auftrete, wird von Müller bestritten. An Hand klinischer Fälle und auf Grund experimenteller Studien am Hund wird vielmehr dargetan, daß bei Markexstirpation sowohl wie bei einfacher Quertrennung stets das Bild der Rententio urinae mit Ischuria paradoxa, bezüglich der Kotentleerung, die uns hier in erster Linie interessiert, gewisse Beschwerden vorliegen, die sich bei festem Kot in Obstipation, bei flüssigem oder breiförmigem Kot in Inkontinenz änßern. Später 
sollen periodische Stuhl- und Urinentleerungen an Stelle dieser Störungen treten. Auf Grund der erwähnten klinischen Beobachtungen und Experimente erklärt Müller die Lehre von der spinalen Lokalisation der Zentren für Blasen- und Mastdarmentleerung als falsch; er verlegt diese Zentren außerhalb des Rückenmarks; im Sacralmark sollen nur Ganglienzellgruppen für die Sphinkteren, also hauptsächlich für die quergestreiften Sphinkteren, vorhanden sein. M üller ist geneigt, die letzten Zentren für die Blasen- und Mastdarmentleerung in die sympathischen Geflechte und Ganglien des Beckens zu verlegen.

Diese Resultate, zu denen Müller kommt, bedeuten jedenfalls nicht das letzte Wort in der Frage. Erstens hat Müller die aus dem Lumbal- und untersten Thorakalmark kommende, im Hypogastricus verlaufende sympathische Innervation nicht hinreichend berücksichtigt (Cohnheim, in Nagels Handb. d. Physiol.) Auch die Arbeiten von $\mathrm{Pal}$ lassen annehmen, daß von höher oben Bahnen zum Rektum und zu den Sphinkteren verlaufen, da Reizung der Splanchnici und des Vagus am Halse nach Trennung des Rückenmarks Bewegungserscheinungen am Rektum auslösten. Wir konnten ferner konstatieren, daß bei einem Hunde mit exstirpiertem Sacral-, Lumbal- und unterem Dorsalmark der Sphincter internus schon kurz nachdem das Tier als der Narkose erwacht war, wieder einen zum Schlusse (inspektorisch) des Anus genügenden Tonus besitzt, während bei einem Hund, bei dem durch Injektion von Novokain in den Duralsack eine hoch nach oben gehende - bis in das Gebiet des Trigeminus reichende - Anästhesie erzielt worden war, so daß die Lähmung sich jedenfalls auch über das obere Dorsal- und das Cervicalmark erstreckte ${ }^{1}$ ), der Sphincter internus weit klaffte. Das spricht ebenfalls dafür, daß der Sphincter internus Fasern von höheren Partien des Rückenmarks bezieht. Dazu kommt, daß die Müllerschen Versuche in ihren Resultaten den Beobachtungen widersprechen, welche Lewandowsky und Schultz an Hunden machten, denen die Hypogastrici und Erigentes durchtrennt worden waren; diese Hunde zeigten echte Inkontinenz der Blase und des Rektums, verbunden mit Mastdarmtenesmen. Auch wir haben einen Hund ${ }^{2}$, dessen Rektum und Blase vollständig vom Rückenmark isoliert worden war (I)urchtrennung der Hypogastrici, Erigentes, aller Sacralwurzeln und des Grenzstranges) längere Zeit

1) Vgl. Protokoll über Versuchstier Nr. 4.

2) Nr. 5 . 
beobachtet, und dabei gefunden, daß der Hund dauernd eine echte Blasen- und Rektalinkontinenz zeigte (l. cf.). Wenn sich der Analschluß mit der Zeit besserte, so beruhte das einfach darauf, daß der autonome Tonus des Sphincter internus sich allmählich hob, und zugleich durch die Schrumpfung des Sphincter externus infolge der teilweisen Degeneration das Lumen des Analrings sich etwas verengerte. Dagegen konnten auch wir konstatieren, daß sich der T'onus des Rektums innerhalb eines Monats ganz sichtlich besserte, die Lähmung des Rektum blieb aber eine dentliche und unzweifelhafte. Dals die sympathischen Ganglien für eine geregelte Entleerung des Mastdarms nicht entscheidend sind, geht daraus hervor, daß Lähmung dieser Ganglien durch Nikotin nach FranklHochwart und Fröhlich den 'Tonus der Sphinkteren bestehen läßt, sowie aus der Beobachtung von Lewandowsky und Schultz, daß gerade bei Tieren, bei denen nach Durchschneidung der Erigentes und Hypogastrici noch die Entfernung des Ganglion mesent. inf. sowie der Plexus hypogastricus angeschlossen wurde, am Verhalten von Blase und Mastdarm sich nichts änderte.

In neuester Zeit erschien eine Arbeit von Roussy und Rossi, welche die Müllerschen Anschauungen direkt zll widerlegen geeignet erscheint. Die Verfasser haben an einer Reihe von Affen den Conus mednllaris teils mit, teils ohne Cauda equina abgetragen und dabei gefunden, daß die so operierten Tiere eine Woche bis 5 Monate nach der Operation bedeutende Störungen der Miktion und Defäkation zeigten.

Vor allem muß man auch darauf hinweisen, daß die Art der Blasen- und Mastdarmentleerung, welche die Versuchstiere Müllers nach der Markexstirpation noch auf wiesen, sich mit dem normalen kntleerungsmechanismus in keiner Weise vergleichen lassen. Diese Hohlorgane müssen sich schließlich durch die vis a tergo entleeren, und daß diese Entleerungen nicht kontinuierlich, sondern in gewisser Periodizität vor sich gehen, liegt beim Rektum schon daran, daß nur periodisch Kot in die Ampulle tritt und daßs die Ampulle als Reservoir größere Kotmengen zu fassen vermag. Hinsichtlich der Blase sei nur darauf hingewiesen, daß auch bei ganz aufgehobenem Tonus nicht notwendig die Blase dauernd leer gefunden werden müßte, da bei fehlender Wandspannung auch größere Flüssigkeitsmengen nur einen minimalen Druck ausüben. Für unser objektives Urteil ist der Blasen- und Mastdarmentleerungsmechanismus der Müllerschen Versuchstiere ein hochgradig gestörter. Vgl.z. B. Protokoll über Müllers Versuchstier Nr. III! Erwähnen wir noch, daß auch aus 
dem reichen Material von Querläsionen, welches Kocher in den "Grenzgebieten" publizierte, zweifellos hervorgeht, daß hinsichtlich des Verhaltens von Blase und Mastdarm ein deutlicher Unterschied besteht zwischen den Fällen, bei denen die Läsion im Brust- und Halsmark sitzt, und den Fällen von Zerquetschung des Lumbaloder Sacralmarks: bei der ersteren Gruppe ausuahmslos Retentio urinae et alvi, bei der zweiten Gruppe Incontinentia alvi und verschieden hochgradige Schwäche des Sphincter ani schon bei Läsionen im Bereich des Lumbalmarks, während erst bei Quetschung des 3. und 4. Sacralsegments auch Incontinentia urinae auftritt. Ob Inkontinenz oder Retention hängt vom Grade der Lähmung der quergestreiften Sphincteren ab, beim Rektum überdies von der Konsistenz der Fäkalien. Mit Recht bemerkt deshalb Kocher, daß der oft scheinbar prinzipielle Unterschied zwischen Blase und Rektum hinsichtlich ihres Verhaltens bei Querläsionen nur ein quantitativer sei.

Wir sind ganz mit Müller einverstanden, wenn er sagt, daß das Zentrum für die Defäkation, das in den Conus verlegt wird, in Wirklichkeit nur ein Zentrum für den Sphinkterreflex sei, halten es aber für verfehlt, dieses eigentliche letzte Defäkationszentrum in den Beckensympathicus verlegen zu wollen ${ }^{1}$ ). Sahli bemerkt in seinem Lehrbuch der klinischen Untersuchungsmethoden zu der Müllerschen Auffassung: „Es geht aus den M.schen Versuchen, wie aus denjenigen von Goltz und Ewald nicht mit Sicherheit hervor, ob wirklich nach der Zerstörung des Rückenmarks die Blasen- und Mastdarmfunktionen mit der nämlichen Kraft und Präzision vor sich gehen, wie zuvor, und ob nicht vielleicht auch die Kraft der glatten Sphinkteren sowohl als diejenige der Detrusoren dabei gelitten hat, ob ferner der Füllungsgrad der Blase und des Mastdarms bis zum Momente der Entleerung sich ohne die Mitwirkung des Marks gleich verhält wie mit derselben."

Wir müssen nach unserer Beobachtung am Versuchstier $5^{2}$ ) die erste und dritte Frage mit Bestimmtheit verneinen, die zweite Frage bejahen und sind dabei in Übereinstimmung mit Lewandowsky und Schultz sowie mit Roussy und Rassi (l. cf.). Wenn Müller ein letztes Defäkationszentrum im Sympathicus anzunehmen geneigt ist, so fällt er prinzipiell in den gleichen Fehler, wie die Vertreter

1) Wir werden in einer späteren Arbeit auf die Frage des ,extraspinalen Steuerungsmechanismus für Blase und Rektum" mit spez. Berücksichtigung der Müllerschen Versuche zurückkommen.

2) Sowie nach genauerem Studium der Müllerschen Versuchsprotokolle. 
der Lehre des spinalen Defäkationszentrums. Es entspricht dem komplizierten Innervationsapparat des Rektums und der Sphinkteren mit den aus verschiedener Höhe des Marks ${ }^{1}$ ) austretenden zentrifugalen und in verschiedener Höhe in dasselbe eintretenden zentripetalen Fasern und mit den verschiedenen sympathischen Ganglienzellstationen viel besser, nach dem Vorschlage Sahlis anzunehmen, daß der Reflexmechanismus des Mastdarms, wie der Blase, aus etagenförmig übereinander geschalteten Reflexbahnen sich aufbaut. Der unterste derartige Reflexbogen liegt dann nicht im Sympathicus, sondern in den autonomen, in der Darmwand (und den Sphinkteren) gelegenen Nervenelementen, welche dem peristaltischen Reflex vorstehen. Sobald einer dieser Bogen gestört ist, resultiert eine Störung, die, je nach dem Sitz und dem Grad der ursächlichen Läsion verschieden, sich verschieden rasch und verschieden vollständig wieder restituieren kann. Allgemeingültige Regeln lassen sich dabei nicht aufstellen. So kann z. B. bei einer Quermyelitis oberhalb des Lumbal- bzw. Sacralmarks der Reflex des Sphincter ani hochgradig gesteigert sein; entsprechend besteht hartnäckige Obstipation, so daß der Spinkter vor jeder Stuhlentleerung manuell dilatiert werden muß, wie wir das letzthin in einem Falle luetischer Myelitis des Dorsalmarks sahen. Der gleiche Patient ist bei flüssigem Rektalinhalt inkontinent, weil er hier zum Zurückhalten des Stuhls der willkürlichen Innervation des Sphincter externus bedürfte. Dagegen kann ein Patient mit Läsion im Lumbalmark, der bei erhaltenem (aber wohl herabgesetztem) Sphinkterreflex und geschlossenem Anus die Erscheinung zeigt, daß bei Einführung des Fingers das Rektum und der Sphinkter erschlaffen, schon gegenüber festem Kot inkontinent sein, obschon es sich hier sicher nicht um eine eigentliche Läsion des Sphinkterzentrums handelt (vgl. Kochers Kasuistik der Querläsionen, loc. cit., Fall 66). Solche Difterenzen lassen sich an Hand eines allgemeingültigen Schemas nur dann erklären, wenn man das Sahlische Schema der übereinander geschalteten Reflexbahnen akzeptiert. - Ein Glied in dieser Kette, event. nur ein parallelgeschalteter Nebenbogen, ist die von uns nachgewiesene Aktivierung des Sphincter internus durch den Sphincter externus. Die Erklärung dieses Vorganges dürfte nach den vorstehenden Betrachtungen nicht mehr große Schwierigkeiten bieten. Wir mü̈ssen bei der Erklärung in erster Linie der Tatsache Rechnung tragen, daß wir in unsern Experimenten an der Innervation der Sphinkteren

1) Sowie des Grenzstranges. 
nichts änderten; es wurde einfach der Sphincter externus getrennt, und so die Kontraktion dieses Muskels und damit die Wirkung dieser Kontraktion auf den Sphincter internus zum Wegfall gebracht. Die Wirkung des Externus auf den Internus kann somit nur eine mechanische sein: d. l. durch die Kontraktion des den Sphincter internus überlagernden Externus wird der glatte Sphinkter mechanisch gereizt und zur Kontraktion und Nitwirkung am Analschluß angeregt. Diese Erklärung ist die naheliegendste und vom physiologischen Gesichtspunkte aus durchaus einwandfrei. So sagt P. Grützner in einer einschlägigen Darstellung (Ergebnisse der Physiologie von Asher und Spiro 1904, Bd. 2, S. 60 und 61): „Es ist leicht zu zeigen, daß der glatte Muskel gegenüber mechanischen Reizen sehr empfindlich ist. Berührungen, schnelle Spannungsveränderungen, Kneifen mit einer Pinzette, lösen bei erregbaren Präparaten und Organen Zusammenziehungen aus." Auch Lando is weist in seinem Lehrbuch darauf hin, daß die Peristaltik durch Pressen (also ebenfalls durch einen mechanischen Reiz) angeregt wird bei der Defäkation, und daß durch willkürliche, kurze Bewegungen des Sphincter externus und Levator ani der Plexus myentericus des Rektums angeregt werden könne. Ähnlich sagt Müller (loc. cit.) „Zum Schlusse der Defäkation kontrahiert sich der Sphincter externus kräftig, und regt dadurch den innern Afterschließer wieder zur Kontraktion an, welcher in dieser dann tonisch verbleibt." - Man könnte einwenden, daß dann auch durch den mechanischen Reiz der Fingereinführung in das Rektum der Sphincter internus zur Kontraktion angeregt werden sollte. Es ist jedoch zu bedenken, daß ein Reiz, wie ihn die Berührung der Darmmucosa mit einem festen Körper darstellt, eben den typischen peristaltischen Reflex auslöst, also Kontraktion oberhalb, Erschlaffung im Bereich des reizenden Körpers und unterhalb desselben. Etwas ganz anderes ist die von Sokoloff und Luchsinger an herausgeschnittenen Ureteren demonstrierte Tatsache, daß durch Spannung vom Lumen her - Überdehnung durch injizierte Flüssigkeit muskulöse Hohlorgane zur Kontraktion angeregt werden können (cit. aus Asher und Spiro, Ergebnisse, Bd. 2, 1904, S. 60 und 61). Wir folgen also einer üblichen physiologischen Annahme, wenn wir die Erregung des Sphincter internus durch den Externus einem mechanischen, auf die intramuskulären Zentren (Plexus) wirkenden Reiz zuschreiben. Schaltet man die Wirkung des äußern Analschließers aus, so verhält sich der Sphincter internus wie die übrigen Partien des Rektums, d. h. er ist 
im wesentlichen den Gesetzen der Peristaltik unterworfen: er dilatiert sich somit, sobald Mastdarmkontenta in seinen Bereich treten. Deshalb müssen Leute mit zerstörtem oder in seiner Kontinuität getrenntem Sphincter externus notwendigerweise inkontinent sein. Wohl steht der Sphincter internus durch die Erigentes mit dem Rückenmark in Verbindung, doch entspricht diese Verbindung nicht der gewöhnlichen spinalen Innervation, vielmehr stellt dieser Innervationsweg das nach $\mathrm{Langley}$ sogenannte sacrale autonome System dar, welches sympathischer Natur ist (Nikotinversuche!). Entsprechend vermissen wir einen prompten, dem Reflex des Externus analogen Sphincter-internus-Reflex. Der eigentliche Wächter des Analschlusses ist deshalb der quergestreifte Sphincter externus; wir haben oben gesehen, dals er auch zahlenmäßig den Hauptanteil an der tonischen Schlußkraft des Afterschlußrings hat. Es scheint althergebrachter Lehre zu widersprechen, daß ein quergestreifter, dem Willen unterworfener Muskel einer permanenten, tonischen Leistung vorstehen soll; dabei ist jedoch, wie oben auseinandergesetzt, nicht außer acht zu lassen, dab der Sphincter externus in vielen Beziehungen ein Verhalten zeigt, das ihn physiologisch der glatten Muskulatur nähert. - 1)er Sphincter internus funktioniert, wenn dem Einflusse des Externus entzogen, als gewöhnlicher Ring. muskel der Rektalwand, den Gesetzen der Peristaltik gehorchend, und ist als solcher nicht in der Lage, der Rektalkontinenz vorzustehen. Doch wird er durch die reflektorische - und willkürliche Kontraktion des Externus zur Zusammenziehung angeregt, so daß er sich am Analschluß aktiv in meßbarer Weise zu beteiligen vermag und nicht etwa nur passiv zusammengedrückt wird. Diese aktive tonische Schlußkraft des Sphincter internus bietet eine wertvolle Komponente in all den Fällen, wo nur geringe Partien des Sphincter externus übrig bleiben und gestattet deshalb, mit relativ geringen Portionen des Sphincter externus, die, z. B. nach alten Dammrissen, plastisch vereinigt werden, eine sehr gute Rektalkontinenz zu erzielen, weil eben nach der Plastik wieder eine mechanische Anregung des Sphincter internus durch die Externuskontraktion erfolgt, und der glatte Splinkter so den Gesetzen der Peristaltik wieder entzogen wird. Es soll durch diese Auffassung natürlich nicht in Abrede gestellt werden, daß bei der willkürlichen Innervation des Sphincter externus nicht auch direkte Impulse auf die Bahnen für den Sphincter internus überspringen, und seinen Tonus erhöhen, wie auch die Hemmung der Sphinkteren bei der Defäkation eine gemeinsame sein wird. Jedenfalls aber kennen wir 
keine prompte reflektorische Reaktion des Sphincter ani internus, die in ihrer Schnelligkeit dem blitzartigen Reflex des Sphincter externus entspräche. Es wäre deshalb auch sehr fernliegend, anzunehmen, daß die Erregnng des Internus durch den Externus auf dem Unwege eines Reflexbogens durch das Rückenmark oder eines Axoureflexes durch die sympathischen Bahnen erfolgte.

Wir glauben in vorstehender Arbeit nachgewiesen zu haben, daß die beiden Teile des Analsphinkters, der glatte und der quergestreifte, die gewöhnlich zusammen besprochen werden, sich funktionell weitgehend differenzieren lassen, und deshalb bezüglich ihrer Funktion auch scharf auseinandergehalten werden müssen. Die Nerven aus dem Sympathicus im engeren Sinne und diejenigen des sacralen autonomen Systems, welche den Sphincter internus innervieren, greifen gleichzeitig auch in den autonomen, intramuskulären Plexus des Rektums ein, während der Dickdarm, auch in seinem untern Teil, eine größere Unabhängigkeit hat und deshalb bei Tieren, denen das Sacral-, Lenden- und untere Brustmark exstirpiert wurde, oder die in den Zustand bis zum Halsmark wirkender Lumbalanästhesie versetzt sind, der stark kontrahierte Dickdarm sich von dem kurzen, dilatierten Rektum scharf scheidet ${ }^{1}$. Entsprechend dieser gemeinsamen Innervation mit dem Reitum ist der Sphincter internus in erster Linie wie dieses den Gesetzen der Peristaltik unterworfen, mit den derbesonderen Funktion der Ampulle als Kotreservoir entsprechenden Modifikationen. Doch wirkt für gewöhnlich der Sphincter internus am tonischen Abschluß des Rektums mit, zum größten Teil angeregt durch die Kontraktion des reflektorisch beim Eintreten von Kot in den untersten Rektalabschnitt prompt reagierenden Sphincter externus, welch letzterem zudem der Hauptanteil am permanenten, reflektorischen Tonus des Analsphinkterrings zukommt. Ist der Sphincter externus in seiner ringformigen Kontinuität getrennt, fällt also die mechanische Anregung des Internus weg, so ist letzterer vollständig den Gesetzen der Peristaltik unterworfen und kann dem Abschluß des Mastdarms nicht in suffizienter Weise vorstehen.

Dieser Auffassung scheint der Umstand zu widersprechen, daß Patienten, die nur noch den Sphincter internus besitzen, festem

1) Vgl. Versuchsprotokolje betr. Hund Nr. 3, S. 113, Hund Nr. 4, S. 115, Hund Nr. 5, S. 116 u. 117 und Huad Nr. 7, S. 120. 
Kot gegenüber unter Umständen kontinent sind. Doch ist dieser Widerspruch nur ein scheinbarer; denn bei nicht hochgradiger Füllung des Rektums ruht selbst beim stehenden Menschen die Kotsäule auf der unteren dorsalen Wand des Rektums, und zwar der unteren Pars horizontalis, der sog. Ampulle, die über dem Kreuzbeinende und dem Steißbein nach vorne zieht. Erst wenn die Füllung der Ampulle eine hochgradige wird, reicht die Spitze der Kotsäule in das von den Sphinkteren umgebene Analstück des Rektums. Nur in diesem Falle kommt der sensible Reiz auf die anale Partie der Rektalmucosa zustande und kann der konzentrische Druck der Sphinkteren im Sinne des Analschlusses sich geltend machen. In diesem Falle aber sind die Patienten, denen der Sphincter externus fehlt, d. h. bei denen er in seiner Kontinuität unterbrochen ist, auch inkontinent, trotz festen, geformten Mastdarminhalts.

Das Verhältnis funktioneller Abhängigkeit zwischen glattem Sphincter ani internus und quergestreiftem Sphincter externus ist in chirurgischer Hinsicht wichtig mit Rücksicht auf die Frage der Analplastik nach Darmrissen oder verletzenden Operationen am Darm und Anus, sei es wegen Tumoren, Prolapsen oder Abszedierungen verschiedener Provenienz.

Die beschriebene Tatsache dürfte auch geeignet sein, auf die Wahl der Operationsmethode bei Fällen von Mastdarmcarcinom einen gewissen Einfluß auszu üben, insofern als es nach dem Gesagten als unstatthaft bezeichnet werden muß, einer Methode zulieb den Sphincter ani externus zu trennen oder gar zu excidieren, sobald sich die Möglichkeit bietet, unbeschadet der Radikalität der Operation den wichtigen Schließmuskel zu schonen. Gegen die Trennung mit nachfolgender Naht wäre prinzipiell ein Einwand nicht zı erheben, wenn die Erfahrung nicht lehren würde, daß die sichere Naht des Externus über dem dicken durchgezogenen Darmende eben sehr schwierig ist und zudem oft die Suturen nicht halten, weil man trotz größter Vorsicht in dieser Gegend nicht immer absolut aseptisch operieren kann und sich das offene Darmlumen in direktester Nachbarschaft der wichtigen Sphinkteruaht befindet.

Eine wirkliche Kontinenz jedoch, ohne daß eine, wenn auch nur kleine Partie des Sphincter externus in gut kontraktionsfähigem Zustande erhalten wird, ist absolut undenkbar.

Deshalb haben auch alle plastischen Methoden zur Verbesserung 
mangelhaften Analschlusses, welche ihren Angriffspunkt nicht in den Sphincter externus verlegen, a priori wenig Aussicht auf Erfolg.

Erhält oder rekonstruiert man dagegen einen Teil des Sphincter ani externus, so garantiert man sich allch die Wirkung des gesamten Sphincter internus, der bezüglich seiner Funktion als Schließmuskel auf die mechanische Anregung von seiten des äußern Schließers angewiesen ist.

\section{Versuchsprotokolle.}

Hund Nr. 1. 19. VI. 1908. Morphin- İthernarkose. Freilegung des Sphincter ani externus durch zwei $1 \frac{1 / 2}{\mathrm{~cm}}$ seitlich vom Anus verlaufende, bogenförmige Schnitte. Stumpfe Isolierung des Muskels unter Vermeidung einer Schädigung des Nervus haemorrhoidalis medius. Dann wird der Muskel vom oberen Rande her sorgfältig stumpf vom Rektum gelöst, soweit möglich, und dann beidseitig in der Mitte quer durchtrennt, bis man die AuBenfläche des Sphincter ani internus vor sich hat. Blutstillung. Fortlaufende Hautnähte.

22. VI. Nachuntersuchung: Wunde sieht gut aus. $\Lambda \mathrm{m}$ Anus sieht man einen 3-4 $\mathrm{mm}$ breiten Schleimhautsaum. Doch ist das Rektum gut geschlossen. Der eingeführte Finger überwindet einen deutlichen Sphinkterwiderstand. Man konstatiert, daß sich das unterste Rektum gut um den Finger schliebt, doch nach einigen Sekunden schon läßt die Kontraktion nach, so daB die Darmwand dem Finger nur noch atonisch anliegt.

24. VII. Nachuntersuchung. Wunde geheilt. Der eingeführte Finger aberwindet einen deutlichen Sphinkterwiderstand. $2 \mathrm{~cm}$ oberhalb des Analrings fühlt man einen zweiten scharfen Kontraktionsring (Sphincter tertius). Nach 10-15 Sekunden löst sich die tonische Kontraktion, und der Darm liegt dem Finger nur noch schlaff an.

29. VI. Nachuntersuchung: Der eingefühte Finger trifft wieder auf einen straffen Sphinkterwiderstand im Niveau des Analrings und auf einen scharfen Kontraktionsring $2 \mathrm{~cm}$ weiter oben. Tonische Kontraktiou des ganzen unteren Rektalabschnittes, soweit der eingefuhrte Finger reicht. Nun wird konstatiert, daB Reizung der Rektalschleimhaut durch Vorstoßen und Zurückziehen des eingefuhrten Fingers stets eine träge Kontraktion des Sphincter internus und tertius zur Folge haben. Doch schon nach 15-20 Sekunden hört diese reflektorische Kontraktion auf, und die Darmwand liegt dem Finger nur noch dicht an, aber ohne Druck.

AnschlieBende Operation: Beidseitig Incision im Bereiche 'der Operationsnarbe und Präparation der retrahierten Stümpfe des Sphincter externus. Dann werden die Stümpfe durch je 3 Knopfnähte vereinigt und so die ringförmige Kontinuitalt des Sphincter ani externus wieder hergestellt. Hautnaht.

1. VIII. Nachuntersuchung: Anus vollständig geschlossen. Der Widerstand for die Einfuhrung des untersuchenden Fingers ist bedeutend gröber als bei der letzten Untersuchung. Kontralktionsring des Sphincter tertius. Jede Bewegung des untersuchenden Fingers am Rektum löst sofort eine reflektorische Kontraktion der Sphinkteren aus. Die tonische 
Kontraktion des untersten Rektalabschnittes dauert zudem an, und löst sich nicht, auch wenn man den Finger mehrere Minuten im Rektum verweilen läßt.

3. VII. Nachuntersuchung: Wunde verheilt; After geschlossen. Einführung des untersuchenden Fingers gegen einen intensiven Sphinkterwiderstand. Man konstatiert wieder die beiden Kontraktionsringe. Jedes VorstoBen oder Zurückziehen des Fingers hat eine blitzartige Kontraktion der Sphinkteren zur Folge. Auch wenn der untersuchende Finger mehrere Minuten im Rektum verweilt, tritt keine Atonie der Darmwand ein, und zudem läßt sich die reflektorische Sphinkterenkontraktion beliebig oft hervorrufen.

9. VII. Nachuntersuchung: Anus vollständig geschlossen, ohne daB ein rektaler Schleimhautsaum sichtbar wäre. Man weist wieder zwei Kontraktionsringe nach, einen breiteren, im Niveau des Analrings und einen zweiten, schmäleren, $2 \mathrm{~cm}$ höher oben, der als Tertiuskontraktion aufgefabt wird. Jede leise Bewegung des Fingers ruft eine reflektorische Kontraktion der Sphinkteren hervor. I)aneben ist das Rektum andauernd tonisch kontrahiert.

Hund Nr. 2. 4. VII.: Morphin- $\mathrm{A}$ thernarkose. Mediane Laparotomie; Vorziehen des Colon und quere Trennung desselben am Übergang in das Rektum, d. h. ca. $8 \mathrm{~cm}$ oberhalb des Analrings. Das obere Darmstück wird in den oberen Winkel der Laparotomiewunde eingenäht, und so ein Anus practernaturalis hergestellt, während das untere Darmende in den unteren Wundwinkel eingepflanzt wird. Zwischen beiden Fisteln wird die Bauchwand etagenweise vernäht. In das eingenähte untere Darmstück wird nun ein mit Gummipfropfen armiertes Glasrohr eingebunden; dieses Glasrohr steht durch einen Gummischlauch mit einem graduierten MeBzylinder in Verbindung. Nach Spülung des Rektums wird in den MeBzylinder Wasser eingefüllt. Sobald nun durch den Schlauch Wasser in das Rektum einflieft, schlieBt sich der Analring reflelitorisch. Nun wird der Wasserdruck durch weiteres Zugießen von Wasser in den MeBzylinder gesteigert: die Sphinkteren halten einen Druck von $190 \mathrm{~mm}$ Wasser; dann wird der AnalschluB gesprengt und das Wasser fließt spritzend aus bis zu einem Druck voll 7,9 bis $8,4 \mathrm{~cm}$. Die Wassersäule von ca. $80 \mathrm{~mm}$ wird nun wieder gehalten. Jetzt wird neuerdings Wasser zugegossen. Dabei zeigt sich zunächst, daß die Flüssigkeitssäule im Rohr nicht ansteigt, obschon kein Wasser per anum entleert wird. Wie die nähere Untersuchung zeigt, füllt sich zunächst das Rektum unter bedeutender Dilatation an; dann erst beginnt bei weiterem Zugießen die Wassersäule im MeBzylinder wiéder zu steigen, und zwar wird wieder genau bei $190 \mathrm{~mm}$ die Druckhöhe erreicht, welche genügt, um den Analschluß zu sprengen. Das Wasser flieBt nun wieder bis zu $80 \mathrm{~mm}$ ab. Mehrmalige Wiederholung dieser Messung ergibt stets ziemlich genau das gleiche Resultat.

Jetzt wird durch einen Bogenschnitt, $1 \mathrm{~cm}$ seitlich vom Anus, der "linke" Musculus sphincter ani externus freigelegt, und nach sorgfältiger stumpfer Isolierung, soweit möglich, in der Mitte quer durchtrennt. Nach Trennung des "linksseitigen queren Sphinkter" kontrahiert sich der Sphincter internus noch zirkulär, und zwar gleichzeitig mit dem intakt gebliebenen rechtsseitigen Sphincter externus. Zur Auslösung einer Kontraktion der Analschlieber genügt die Einführung des Fingers in den Anus; es erfolgt stets prompt ein Schliebreflex. - Nun wird auch die rechtsseitige Hälfte des Sphincter externus noch quer durchtrennt. Dabei fällt nun sofort auf, 
daB jetzt der Anus klafft. Es wird ein $1 / 2 \mathrm{~cm}$ breiter Saum der Rektalschleimhaut sichtbar. Fine reflektorische Kontraktion des Sphincter internus ist durch Einfuhrung des Fingers und durch Reiben der Rektalmucosa zunächst uberhaupt nicht melir auszulösen.

Das in den Meßzylinder eingefullte Wasser flieBt sofort per anum ab, das Flüssigkeitsniveau sinkt sofort auf Null herunter.

Hund Nr. 2. 7. VII. Inspektorisch: Anus geschlossen, so daß man nicht in das Rektum hineinsieht; doch liegt immerhin ein ca. ${ }_{12} \mathrm{~cm}$ breiter Saum der Rektalmucosa zutage. Der eingeführte Finger überwindet eine mäBige Kontraktion des Sphincter internus. Nach geeigneter Lagerung des Versuchstiers wird wieder der MeBzylinder in üblicher Weise mit der Rektalfistel verbunden und das Rektum mit Wasser gefüllt, um jetzt die SchlieBkraft des glatten Sphinkters (wesentlich!) beim nichtnarkotisierten Tiere zu messen. Der Hund hält mit seinem glatten Sphinkter anfänglich eine Wassersäule von $107 \mathrm{~mm}$, die jedoch rasch auf $75 \mathrm{~mm}$ absinkt. Nun wird der Meßzylinder neuerdings angefullt; die Flüssigkeitssäule sinkt rasch auf $107 \mathrm{~mm}$, wo erstmaliger Stillstand eintritt. Dann sinkt das Niveau der Flüssigkeitssïule weiter bis zu $71 \mathrm{~mm}$. Jetzt wird der Meßzylinder bis zu $200 \mathrm{~mm}$ angefüllt; das Flüssigkeitsniveau sinkt rasch auf $105 \mathrm{~mm}$, wo wieder kurzer Stillstand. Dann weiteres Sinken:

$$
\begin{array}{lcc}
\text { in } 1 \% & \text { Minuten auf } 50 \mathrm{~mm} \\
\text { in } 2 & &
\end{array}
$$

Dann ganz langsames Absinken "des Wassers. Nach 15 Minuten steht das Flüssigkeitsniveau auf $30 \mathrm{~mm}$.

Nochmalige Füllung auf $100 \mathrm{~mm}$; sofortiges Absinken des Niveaus auf $30 \mathrm{~mm}$. Bei wiederholten Füllungen sinkt die Flüssigkeit stets sofort auf $30 \mathrm{~mm}$ Druck ab.

9. VII. Nachuntersuchung von Hand Nr. 2: Anus geschlossen. Der eingefuhrte Finger fühlt deutlich die Kontraktionszone des Sphincter internus. Doch schon nach ganz kurzer Zeit (15 Sekunden) erschlafft diese Kontraktion und man fuhlt nur noch einen schwachen Druck im Bereiche der untersten $2 \mathrm{~cm}$ des Rektums. Oberhalb ist der Darm erheblich dilatiert. Reizung der Rectalmukosa durch Vorschieben und Zurückziehen des untersuchenden Fingers ruft ebensowenig wie Druck gegen eine Seite der Darmwand reflektorische Kontraktion des Sphinkters hervor. Jetzt wird in ubblicher Weise das in die Bauchwand eingenähte obere Rektalende mit dem MeBzylinder verbunden, um die Schließkraft des Sphincter internus allein beim nicht narkotisierten Tiere zu messen. Dabei wird man darauf aufmerksam, daB das Tier eine ziemlich bedeutende Flüssigkeitssäule (260 mm) halten kann durch Anpressen der Schwanzwurzel gegen den Anus. Diese Fehlerquelle wird dadurch ausgeschaltet, daB der Schwanz in horizontaler Lage fixiert wird. Der Hund hält mit seinem Sphincter internus $70-100 \mathrm{~mm}$ Wasserdruck; nach kurzer Zeit fängt das Flüssigkeitsniveau im MeBrohr wieder an zu sinken, and zwar bis auf $45 \mathrm{~mm}$. Eine weitere, für den differenten Mechanismus des Sphincter internus gegenüber demjenigen des Sphincter externus beweisende Beobachtung ist die, daB Einfuhrung des Fingers — von auBen - in das Rektum stets vollständige Entleerung der durch die Schließkraft des glatten Sphinkters und des Rektums vorher noch gehaltenen Wassermenge zur Folge hat. 
Darch die Einfahrung des Fingers wird somit ein Entleerungsreflex ausgelöst, oder mit anderen Worten, um nichts zu prajjudizieren: sobald die tonische Schliebkontraktion des glatten Sphinkters durch Einfuhrung des Fingers unterbrochen wird, flieBt alles Wasser ans.

Hund Nr 3. 9. VII. Morphin-Ãthernarkose. Mediane Laparotomie in der unteren Hälfte der Linea alba. Vorzichen des Dickdarms, Isolierung eines $2 \mathrm{~cm}$ langen Stackes am Übergang des Colon descendens in das Rektum, unter Ligatur einiger Mesenterialgefäße, und quere Trennung des Darms. Das obere Darmende wird in den oberen Wundwinkel eingenäht, in ablicher Weise, das untere Ende in den unteren Wundwinkel. Dazwischen schichtweise Naht der Bauchwand, so daB man also einen Anus praeternataralis und eine Rektalfistel hergestellt und das Rektum isoliert zu Untersuchungszwecken zur Verfügung hat, wie beim vorigen Versuchstier.

Versuch mit Hund Nr. 3. 10. VII. nachmittags. Verbindung des Rektums mit dem Mebzylinder in üblicher Weise. Beim FingieBen von Wasser ins Rektum erfolgt eine reflektorische Schliebkontraktion des Analringes. Der Hund hält anfänglich mit seinen Sphinkteren $380-420 \mathrm{~mm}$ Wasser. Wiederholte Versuche ergeben, da $B$ die durch reflektorische Kontraktion des Analsphinkters gehaltene Wassersäule $380 \mathrm{~mm}$ betrăgt. Wird dieser Druckwert durch weiteres Zugießen von Wasser überschritten, so beginnt sich das Rektum zu entleeren, und zwar findet dabei nicht etwa eine Dilatation des Analringes statt, sondern derselbe öffnet sich nur so weit, daB ein kräftiger Wasserstrahl herausspritzt, wobei der Sphinkter stets in einem leicht schwankenden Kontraktionszustande bleibt. Die Entleerung geht verschieden weit, wird aber nie vollständig.

13. VII. Versuch mit $\mathrm{Hund}$ 3: Verbindung des Rektums mit dem Meßzylinder in ablicher Weise. Man läßt langsam Wasser in das Rektum einfließen und beobachtet auf den Reiz des einfließenden (körperwarmen) Wassers eine reflektorische Kontraktion der Sphinkteren. Bei jeder plötzlichen Vermelirung des Wasserdrucks erfolgt eine prompte, reflektorische Kontraktion des "Analrings".

Bei einer Druckhöhe von $350 \mathrm{~mm}$ wird der AnalschluB gesprengt and das Wasser fließt spritzend aus bis zu einem Druckwert von $230 \mathrm{~mm}$.

Es wird bei der Einfüllung konstatiert, in Analogıe zu dem beim Versuchstier Nir. 2 festgestellten Verhalten, daß von einem gewissen Druckwert an das Rektum dilatiert, der Tonus der Rektalwandmuskulatur also aberwunden wird, während der Sphinkterenring noch einer bedeutenden Steigerung des Wasserdruckes standhält.

Die Messung wird nun mehrmals wiederholt und dabei konstatiert, da $B$ ein Wasserdruck von $350-380 \mathrm{~mm}$ gehalten wird; bei Übersteigen dieses Druckes beginnt das Wasser auszufließen, und zwar stets bis zu einem Druckwert von $230-240 \mathrm{~mm}$ Wasser. Die Finfuhrung des Fingers in den geschlossenen Analring hat eine starke reflektorische Kontraktion des Sphinkterenringes zur Folge; beim Herausziehen des Fingers spritzt momentan etwas Wasser heraus, dann kontrahiert sich aber der Analring wieder lräftig und die ganze Flüssirkeitssäule wird wieder unverändert gehalten.

Versuch: Einleitung der Narkose mit Chloroform-ĩther (weil der IIund kein Morphium bekam) und Fortsetzung der Narkose mit ither 
bis zur Aufhebung der Cornealreflexe. Dann wird das Rektum vom MeBzylinder her wieder mit Wasser gefült.

Der tief narkotisierte Hund zeigt nun, wie vorher in wachem Zustande, eine reflektorische Kontraktion der Sphinkteren auf den Reiz des einfließenden Wassers und bei intermittierender Steigerung des Druckes. Die reflektoriseh gehaltene Flüssigkeitsmenge beträgt bei 3 aufeinanderfolgenden Messungen $260 \mathrm{~mm}$ Wasser $285 ", \quad "$ $260 ", "$

Wird der auf den Sphinkteren ruhende Wasserdruck aber diese Werte hinaus gesteigert, so fließt das Wasser aus dem Rektum spritzend aus, bis zu cinem Drucke von

$\begin{array}{ccc}180 & \mathrm{~mm} & \text { Wasser } \\ 190 " & " \\ 190 & \end{array}$

Einführang des Fingers löst eine Kontraktion des Sphinkterenringes aus, wie beim nichtnarkotisierten Tier, und beim Herausziehen des Fingers spritzt momentan etwas Wasser aus, ohne daß eine wesentliche Entleerung des Darmes stattfindet.

Versuch: In derselben Narkose wird der linksseitige Sphincter externus von einem pararektalen, seitlichen Bogenschnitt aus freigelegt und sorgfältig vom Sphincter internus isoliert; dann wird der betreffende Teil des quergestreiften Sphinkter durchschnitten. Der Anus öffnet sich dabei etwas, so daß ein schmaler Saum der Rektalmucosa sichtbar wird. Dann wird auch der rechtsseitige Sphincter externus freigelegt und in gleicher Weise getrennt. Yachdem die Hautwundrïnder wieder in normale Situation gebracht worden sind, wird eine Messung angeschlossen, und konstatiert, daß bei Einfullen von Wasser in das Rektum die Flüssigkeitssäule stets auf das Niveau Null herabsinkt.

14. VII. Versuch: Messung der Schlubkraft des Sphincter internus am nichtnarkotisierten Hund. Zunächst wird konstatiert, daB Einfahrung des Fingers eine reflektorische Kontraktion der Externusstümpe und des Sphineter internus zur Folge hat. Die Kontraktion des glatten Sphinkters läßt aber an Intensität rasch nach. Auf EinflieBen von Wasser eine schwache Kontraktion.

Es werden folgende Druckwerte vom glatten Sphinkter gehalten:

$105 \mathrm{~mm}$ Wasser
$85 "$
$85 " \#$.

Bei Mehrbelastung flieBt Wasser per anum ab, aber stets nur bis zu der angegebenen Druckhöhe. Wir finden also hier nicht eine reflektorisch und eine tonisch gehaltene verschiedenartige Druckhöhe wie beim Tier mit erhaltenem Sphincter externus.

Bei Einführung des Fingers eine ganz schwache Kontraktion; beim Herausziehen flieBt sofort alles Wasser bis zum Niveau $=0 \mathrm{ab}$.

Mehrmals wiederholte Versuche ergeben in dieser Hinsicht stets das nämliche Resultat.

Versuch mit Hund Nr. 3. 15. VII. Subkutane Injektion von $0,06 \mathrm{gr}$ Morphium. Nach 45 Minuten ist der Reflex des Sphincter internus noch 
erhalten, und zwar sowohl durch den Reiz des eingefuhrten Fingers auszulösen, wie durch EingieBen von körperwarmem Wasser in das Rektum. Doch genugt die Schlußkraft des glatten Sphinkters nicht, um einen meBbaren Wasserdruck zu erbalten; das Niveau der Flüssigkeitssäule im MeBrohr sinkt stets sofort auf den Nullpunkt. Es liegt somit hier eine spezifische, anch anderwärts beobachtete Morphinwirkung auf den Sphinkter vor.

Von Bedeutung ist die auch in diesem Versuche gemachte Beobachtung, daß der anfänglich ziemlich lebhafte reflektorische Schluß des glatten Sphinkterrings schon nach kurzer Zeit schwächer wird und bald ganz aufhört.

Versuch mit Hund Nr. 3. (anschließend). Mit Rácksicht auf die Entscheidung der Frage, ob etwa der differente Reflex des Internus auf anderen, d. h. tieferen, außerhalb des Rúckenmarks verlaufenden Bahnen sich abspiele, so unwahrscheinlich eine derartige Annalume auch ist, und um zu sehen, wie weit der Internustonus vom Räckenmark abhängig sei, wird dem Hunde der ganze Wirbelkanal vom Sacrum bis zum 2. Brustwirbel durch Laminektomie eröffinet und das ganze Rückenmark vom 2. Brustwirbel abwärts entfernt. Das Tier befindet sich dabei in tiefer Äthernarkose. Sofort nach Entfernung des Ruckenmarks steht der Anus weit klaffend offen, der unterste Abschnitt (ca. $5 \mathrm{~cm}$ ) des Rektums ist ganz schlaff. Naturlich keine Spur von Reflexen.

Eine Nachuntersuchung, 6 Stunden nachdem das Tier aus der Narkose erwacht ist, ergibt folgendes Resultat:

Der Anus ist jetzt wieder so weit geschlossen, daB man nicht in das Rektum hineinsieht. Man erblickt nur einen schmalen, etwa $1_{2}^{1 / 2} \mathrm{~cm}$ breiten Saum von Mastdarmschleimhaut, genau wie bei einfacher Durchtrennung des Sphincter externus. Der Einführung des Fingers begegnet nur ein ganz minimaler Widerstand, der etwa der Elastizitätskomponente entsprechen dürfte. Sehr auffällig ist nun, daß man $5 \mathrm{~cm}$ oberhalb des Analrings auf einen ganz scharfen Kontraktionsring stöBt, durch den das Colon descendens gegen das Rektum hin scharf abgetrennt und abgeschlossen ist. Mit langsamem Fingerdruck läßt sich dieser Kontraktionsring überwinden und man konstatiert, da $B$ im Gegensatz zu dem ganz schlaffen Rektum der anschlieBende Dickdarm trotz Entfernung des Ruckenmarks bis zur angegebenen Grenze sich in guter, tonischer Kontraktion befindet. Die SchluBkraft des Analrings für Wasser ist natürlich gleich Null.

Versuch mit Hund Nr. 4. Mit Rücksicht auf den Untersehied im Kontraktionszustand des Rektums und Colon descendens bei Entfernung des Brust- und Lendenmarks soll bei diesem Versuchstier durch weit nach oben wirkende Lumbalanästhesie eine noch weiter nach oben reichende motorische Lähmung hervorgerufen werden, um eventl. Auskunft über die Provenienz der versorgenden Fasern zu bekommen.

17. VII. Morphium- $\Lambda$ thernarkose. Entfernung des Dornfortsatzes des 2., 3. und 4. Lendenwirbels. Eröffnung des Wirbelkanals und Freilegung des Duralsackes auf eine Strecke von $2 \mathrm{~cm}$. Tamponade und provisorischer Schlub der Wunde.

AnschlieBend mediane Laparotomie im unteren Drittel der Linea alba, Vorziehen des Dickdarms und quere Trennung desselben etwa $8 \mathrm{~cm}$ oberhalb des Analrings nach Isolierung der betreffenden Stelle vom Mesenterium. Dann wird 
seitlich rechts permuskulär incidiert und das obere Ende des Darms durch diese zweite Öffnung in der Bauchwand vorgezogen nnd eingenäht, um so einen separaten Anus praeternaturalis zu gewinnen. Das untere Darmende wird in üblicher Weise in den unteren Wundwinkel der medianen Wunde eingenäht und die Bauchwunde im übrigen geschlossen.

18. VII. Versuch: Messung der SchlieBkraft beider Analsphinkteren in oben beschriebener Weise: Der Hund hält anfänglich $550 \mathrm{cmm}$ Wasser. Bemerkenswert ist, daB bei hoher Belastung (zwischen 500 und $550 \mathrm{cmm}$ ) rhythmische Kontraktionen der Sphinkteren und der Beckenbodenmuskulatur (Levator ani und Coccygei) auftreten bevor der AnalschluB durch den Wasserdruck gesprengt wird.

5 Minuten später, nachdem dic Muskulatur vollständig zur Ruhe gekommen ist, werden 400 bis $420 \mathrm{cmm}$ Wasser gehalten, bei einer dritten Messung $450 \mathrm{cmm}$. Bei Übersteigung dieser Druckwerte fließt das Wasser spritzend aus und zwar bis zu einem Druck von

$350 \mathrm{~mm}$

$260 \mathrm{~mm}$

$300 \mathrm{~mm}$.

Nun wird noch geprüft, wie Finführung des Fingers ins Rektum von außen wirkt. Dabei zeigt sich in C̈bereinstimmung mit früheren Beobachtungen, da $B$ sich der Sphinkterenring kräftig reflektorisch um den eingeführten Finger kontrahiert, und daß beim Herausziehen des Fingers nur momentan etwas Wasser aus dem Rektum herausspritzt; sofort findet wieder kräftiger Analschluß statt und die ganze Wassersäule wird unverändert gehalten. Solange der Sphincter externus intakt ist, wird somit durch Fingereinführung kein Entleerungsmechanismus ausgelöst, während dies dort, wo nur noch der Sphincter internus funktionstuchtig ist, stets der Fall war (vgl. Versuchsprotokoll von IIund 2 und 3).

Weitere Konstatierungen, die ein gewisses Interesse beanspruchen, sind bei diesem Versuch noch die folgenden:

Bei langsam steigendem Druck wird auch hier zuerst der Tonus der Rektalwandmuskulatur überwunden: es findet zunächst eine bedeutende Dilatation des Rektums statt. Dann wird die Analgegend stark vorgebuchtet, eine Bewegung, die im wesentlichen gegen die Aktionsrichtung des M. levator ani vor sich geht; jetzt erst wird der Sphinkterenwiderstand überwunden und zwar spritzt das Wasser in liäftigem Strahle heraus. Man beobachtet nicht etwa eine einheitliche Dilatationsbewegung der Analsphinkteren, sondern die Muskeln des Analrings befinden sich in schwankender Kontralition. Man kann ganz deutlich einzelne kurze in rascher $\Lambda$ ufeinanderfolge auftretende Kontraktionen des Sphinkterrings beobachten, Kontraktionen, die jedoch nicht genügen, um den Strom des ausfließenden Wassers zu unterbrechen, bis die angegebene untere Grenze des Wasserdruckes erreicht ist.

Diese Beobachtung wurde auch bei den früheren Versuchstieren stets erhoben, wenn auch nicht so exquisit, wie bei Versuchstier Nr. 4.

Za dem nun folgenden Versuch der Lumbalanästhesierung muBten wir den Hund zunächst mit einigen Tropfen Chloroform betäuben, weil die Dura dermaßen empfindlich ist, daB ruhiges Anstechen mit der Nadel unter sicherer Vermeidung einer Verletzung des Marks nicht möglich gewesen wäre.

Versuch: öffnung der Wunde am Rücken, Freilegung der Dura 
und Injektion von $0,7 \mathrm{ccm}$ einer 2 proz. Lösung von Novokain mit Adrenalin in den Subduralraum, unter sicherer Vermeidung jeglicher Nebenverletzung. Dann wird das Tier, das sofort aus der Choroformbetäubung erwacht, ganz kurze Zeit an den Hinterextremitäten emporgehalten; damit soll bewirkt werden, daB die Novokainwirkung möglichst weit nach oben sich geltend machen kann.

Nach 2 Minuten sieht man am Anus einen Schleimhautsaum wie bei Durchtrennung des Sphincter externus. Nach 3 Minuten ist auch die Wirkung des Sphincter internus aufgehoben, der Anus steht klaffend offen, so daB man tief ins Rektum hineinsieht, wie beim toten Tier, oder beim Tier unmittelbar nach Exstirpation des Sacral-, Brust und Lendenmarks. Der Dickdarm befindet sich in guter, tonischer Kontraktion und setzt sich scharf gegen das schlaffe Rektum ab. Die Reflexe (auf Fingerdruck und Reiz des einfließenden Wassers) sind schon zwei Minuten nach der Injektion aufgehoben, und eine Messung der AnalschluBkraft mit dem MeBzylinder gibt schon in diesem Moment Abfallen der Wassersäule auf Null. Zugleich mit der Lähmung der Rektalsphinkteren tritt motorische und sensible Lähmung der hinteren Extremităten auf. In ganz kurzer Zeit schreitet nun die Anästhesie über den ganzen Körper nach oben fort; 15 Minuten nach der Injektion kann man den Hund in die Pfoten, in die Ohren und in die Nase stechen, ohne daß er etwas fuhlt. Auch die Sensibilität der Mundschleimhaut ist aufgehoben. Erhalten ist nur noch eine ganz minimale Sensibilität der Zunge. Auch besteht ein schwacher Cornealreflex und ein schwacher Lidreflex bei Stechen in Bereich der Schnauze und in der Umgebung der Augen. Die vorderen Extremitäten werden starr ausgestreckt gehalten; auf ein zwischen die Zähne eingefuhrtes Stück Holz beißt das Tier kräftig, wie tetanisch zusammen. Pupillen weit, Puls am Herzen ruhig und regelmäßig; Atmung: reine Zwerchfellatmung. Der Hund kann nur auf der Seite liegen.

Nach 2 Stunden beginnt der Hund wieder unbeholfene Gehversuche zu machen, fällt aber stets wieder um.

Nachuntersuchung $31 / 2$ Stunden nach der Injektion: Sensibilität überall wieder vorhanden. Es besteht deutliche Hyperalgesie! Der IIund kann wieder sicher gehen; eigentümlich ist dabei, das die Hinterpfoten bei jedem Schritt wie federnd in die Höhe schnellen. so daß der IIund hinten wie auf Federn zu gehen scheint, während an den Vorderextremitäten nichts Entsprechendes zu konstatieren ist. Dieses Phänomen beruht, wie nähere Untersuchung zeigt, auf einer bedeutenden Steigerung der Reflexe.

Das Rektum ist nach außen hin durch den Analring wieder fest abgeschlossen. Man fühlt eine kräftige Kontraktion der Analsphinkteren und konstatiert, daB auch der Sphinkterreflex deutlich gesteigert ist.

Nun läßt man langsam Wasser ins Rektum laufen, sofort tritt am Anus eine rasche kräftige Kontraktion des Sphinkters auf. Die SchluBliraft entspricht einer Wassersäule von $300-320 \mathrm{~mm}$. Wird dieser Druckwert überstiegen, so fließt der Inhalt des Darms spritzend aus bis $\mathrm{zu} 240 \mathrm{~mm}$.

Nach Fingereinfơhrung erfolgt eine spritzende Entleerung, ohne daB der ganze Inhalt des Rektums ausfliebt. Das Rektum und das Colon, soweit durch Kontrolle von unten zu konstatieren, sind gut tonisch kontrahiert. 
Der Hund ist etwas unruhig. Die Atmung, ruhig und regelmäßig, zeigt wieder costo-abdominalen Typus. Puls am Herzen regelmäBig. Sensibilität überall wieder vorhanden, Reflexe uberall deutlich gesteigert.

Anderen 'Tags ist der Hund wieder vollständig munter und unterscheidet sich in nichts von einem normalen Tier. Namentlich zeigt das Verhalten der Analsphinkteren keinerlei Abweichungen von der Norm.

Hund Nr. 5. 17. VIII. Morphium-Athernarkose.

Mediane Laparotomie, Entleerung der Blase, Vorziehen des Colon descendens und Aufsuchen des Ganglion mesentericum inferius, was nachdem an mehreren Hundekadavern früher genaue Nervenpräparate bez. der nervösen Versorgung des Rektums angefertigt worden waren - an Hand der Arteria mesent. inf. Ieicht gelingt. Trennung der Peritonealblätter des Mesenteriums und stumpfe Präparation der Nervi hypogastrici, die auf Fadenschlingen gelegt werden. Dann werden die N. hypogastrici nach unten verfolgt und der Plexus hypogastricus aufgesucht; so kann man sich gut über den Verlauf der vom Plexus sacralis zu diesem Plexus verlaufenden Nervi erigentes sive pelvici orientieren. Auch die Erigentes werden beidseitig vorsichtig stumpf präpariert, und sowcit nach hinten verfolgt, bis man an den Plexus sacralis gelangt. Unter Emporheben des Rektums gelingt es, beidseitig, links mit etwas größerer Mühe wegen interkurrenter Blutung, die 1., 2. und 3. Sacralwurzel zu präparieren, und, nachdem jede einzeln auf stumpfem, stark gebogenem Haken emporgehoben worden, mit dem Messer zu trennen. Dic Wurzeln wurden ziemlich dicht an der Austrittsstelle am Knochen durchtrennt; zur größeren Sicherheit wurde $5 \mathrm{~mm}$ lateralwärts noch eine zweite Trennung der Wurzeln angeschlossen. Nun werden noch beide $X$. hypogastrici auf eine Strecke von ca. $1 \mathrm{~cm}$ reseziert, und schließlich noch der Grenzstrang an der Eintrittsstelle ins kleine Becken beidseitig quer durchtrennt. Nach exakter Blutstillung durch temporäre Tamponade wird die Bauchwunde schichtweise vernäht.

Nachdem das 'Tier aus der Narkose erwacht ist, wird der Anus inspiziert. Zunächst fällt auf, daß ein $1 / 2 \mathrm{~cm}$ breiter Saum von Rektalschleimhaut sichtbar ist, wie beim Tier mit getrenntem Sphincter externus. Der eingefahrte Finger findet nicht den geringsten Widerstand im Niveau des Analrings; naturlich ist der Sphinkterreflex erloschen.

Nachuntersuchung 18. VIII. Am Anus ein breiter hellroter Saum von Rektalmucosa. Der eingeführte Finger trifit keinen Widerstand im Niveau des $\Lambda$ nalrings. Rektum schlaff. $5 \mathrm{~cm}$ oberhalb des Anus trifft man auf eine ganz eng kontrahierte Darmpartie, in welche die Fingerspitze nur unter einem gewissen Druck einzudringen vermag. Irgendein Reflex im Bereiche der Analsphinkteren ist nicht auszulösen. Im Analring lag etwas breiiger Kot, Rektum war leer. Das 'Tier bekam zu seiner vollständigen Lälimung des Rektums eine komplette Blasenlähmung. Der Harn träufelt fortwährend ab. Bei jeder brüsken passiven Bewegung (Aufheben) flieBt der Urin rascher ab. Die Blase ist nur mäßig gefullt und läßt sich durch ganz leichten Druck auspresseu.

Nachuntersuchung 19. VIII. Anus etwas offen; man sieht einen $1 \mathrm{~cm}$ breiten Saum Rektalmucosa, ohne direkt in das Rektum hineinzusehen. Es ist somit das Bild eines geringgradigen Prolapses. Der eingefuhrte 
Finger findet keinen Sphinkterwiderstand. Ganz gelegentlich glaubt man eine leise Zuckung des Sphinkters zu fühlen. Keinerlei Reflexe. 5 cm oberhalb des Analrings ist der Darm gut kontrahiert. Im Anus steckt etwas breiförmiger Kot, den das Tier nicht ausstoßen kann. Blase auspreßbar, enthält jedoch nur wenig Urin.

Nachuntersuchungen vom 20. und 21. August ergeben dasselbe Resultat.

22. VIII. Anus offen, ohne daB man in das Rektum hineinsieht. Bei Einführung des Fingers kein Widerstand und kein Reflex. Rektum schlaff; doch ist eine gewisse tonische Kontraktion der Darmmuskulatur zweifelsobne vorhanden. Nachdem man den untersuchenden Finger wieder aus dem Relitum herausgezogen hat, klafft das unterste Ende des Darms, um sich langsam von oben her wieder zu schließen.

24. VIII. Status des Rektums wie bei der früheren Untersuchung. Fs besteht eine tonische Kontraktion der Rektalwandmuskulatur; doch fühlt sich das Rektum für den eingeführten Finger schlaff an. Prolaps hat etwas zugenommen. Im Rektum war ziemlich viel Kot.

Mehrere Nachuntersuchungen ergeben hinsichtlich der Motilität der Sphinkteren und der Rektalwandmuskulatur stets das gleiche Resultat. Das Rektum wird bei der Untersuchung meistens mit Kot angefallt gefunden. Die Blase stets im \%ustande schlaffer Lähmung. Die Abgrenzung des gelihmten, schlaffen Rektums gegen das gut kontrahierte Colon ist stets scharf ausgeprägt. Der Kontraktionsring findet sich immer an gleicher Stelle, ca. $5 \mathrm{~cm}$ oberhalb des Analrings.

Nachuntersuchung vom 23. IX. Laparotomiewunde gut vernarbt. - Blase im Zustande schlaffer Iähhmung; es träufelt konstant Urin ab, und bei leichtem Druck auf die Blasengegend fließt der Urin im Strahle aus. Entsprechend ist das Tier am Hinterkörper stets naB. - Rektum ganz wenig offen, aber kein Prolaps. An Stelle des sonst bei Hunden kräftigen Sphincter externus-Wulstes eine Einsenkung, entsprechend der partiellen Atrophie des Sphincter externus. Der Finger kann, ohne einen erheblichen Spbinlkterwiderstand zu treffen, in das Rektum eingeführt werden, welches voll Kot ist. Rektum schlaft. Keinerlei reflektorische Kontraktion der Rektalwandmuskulatur oder der Sphinkteren auszulösen, weder vom Darm noch von der Analhaut aus. $5 \mathrm{~cm}$ oberhalb des Analrings ist der Darm (Colon) gut kontrahiert und durch eine ringförmige Kontraktionszone vom schlaffen Rektum abgetrennt. Zieht man den eingeführten Finger zurück, so klafft das Rektum, um sich langsam von oben her bis auf eine kleine öffnung zu schließen.

Atrophie im Gebiete aller vom Plexus sacralis versorgten Muskeln.

Hund Nr. 6. 22. VIII. Untersuchung ohne Narkose.

Einfullrung des Fingers in das Rektum gegen starken Sphinkterwiderstand. Im Bereiche der Sphinkteren, also auf eine Strecke von ungefähr $2 \mathrm{~cm}$, ist der Darm sehr stark kontrahiert, weiter oben weniger intensiver Schlue um den Finger. Das Colon, wie gewohnt, $5 \mathrm{~cm}$ oberhalb des Anus durch einen scharfen Kontraktionsring gegen das Rektum abgeschlossen. Reizung der Rektalmucosa durch VorstoBen oder Zuruckiehen des Fingers löst stets eine reflektorische Spinkterenkontraktion aus.

Morphium- ̈̈thernarkose. 
Freilegung des Sphincter externus durch zwei $1 \mathrm{~cm}$ seitlich vom Rektum angelegte Bogenschnitte. Sorgfältige Isolierung des äußeren Sphinkters und quere Trennung beidseitig. Dabei zeigt es sich, daß stets noch gelegentlich eine reflektorische Kontraktion der Darmwand $2-3 \mathrm{~cm}$ oberhalb des Analrings erfolgt. Genauere Untersuchung ergibt, daB diese Kontraktionen ganz dünnen, zirkulären Faserzügen des quergestreiften Sphinkters zukommen, die bis so weit nach oben der Darmwand aufgelagert sind. Auch diese letzten Fasern des Externus werden noch sorgfältig getrennt. Jetzt erfolgen keinerlei prompte reflektorische Kontraktionen mehr. Der Sphincter internus kontrahiert sich gelegentlich ganz schwach. Zur gröBeren Sicherheit wird auch noch beidseitig der Musc. coccygeus und der Levator ani getrennt, die theoretisch, gemäB ihres anatomischen Verlaufes, auch noch einen gewissen VerschluB des Rektums bewirken konnten. 'Tiefe Naht und Hautnaht.

Sobald das Tier etwas aus der Narkose erwacht ist, wird eine Nachuntersuchung angeschlossen. Der Anus ist etwas offen, und zeigt einen $1 / 2 \mathrm{~cm}$ breiten Schleimhautsaum. Der eingeführte Finger 1rifft auf einen deutlichen, dem Sphincter internus zuzuschreibenden Widerstand. Das Rektum schließt sich gut um den eingefuhrten Finger. Gelegentlich fühlt man cine zirkuläre Kontraktion im Bereiche des sog. Sphincter tertius. Reizung der Rektalschleimbaut durch Vorschieben und Zurückziehen des Fingers hat eine leichte Kontraktion des Sphincter internus zur Folge, doch nur $6 \mathrm{mal}$ hintereinander, dam tritt Atonie des untersten Rektalbezirkes ein, und man fühlt auch keine Zusammenziehung des Sphincter internus mehr.

Eine interessante Beobachtung liegt darin, daB der Hund, sobald man ihm den Finger in den Auus einfuhrt, die für die Defäliation typische Stellung einnimmt: halbsitzende Position, Elevation des Schwanzes; zudem beginnt er sofort zu pressen und drückt das Rektum nach unten vor, so daB ein Teil seiner Mucosa zur Erscheinung kommt.

Wir haben hierin also einen typischen, zusammengesetzten Defäkationsreflex, wie er beim IIunde mit intaktem Sphincter externus bei unseren zahlreichen Untersuchungen durch Fingereinführung nicht ausgelöst werden konnte. Im Gegenteil sucht der normale Hund durch Einkneifen des Schwanzes die Einfuhrung des untersuchenden Fingers ins Rektum zu verhindern.

Nachuntersuchung vom 24. VIII: Wunde gut aussehend. Einführung des Fingers in den Anus gegen geringen Widerstand des glatten Sphinkters. Das unterste Rektum schlieBt sich ordentlich um den Finger, doch sind leine prompten Reflexe auszulösen. Vielmehr tritt kurz nach Fingereinfăhrung bedeutende Erschlaffung der Darmwand ein, und der Hund nimmt charakteristische Defäkationsstellung ein. Unter heftiger Anspaunung der Bauchpresse wird der obere Darm (das Colon descendens) in das erschlaffte Rektum hineingepreBt. Mehrmalige Wiederholung der Untersuchung in entsprechenden Abständen hat stets dasselbe Resultat. Man fühlt auch bei diesem Tier einen das Colon gegen das Rektum hin scharf abschlieBenden Kontraktionsring, $5 \mathrm{~cm}$ oberhalb des Anus.

25. VIII. Ganz geringe tonische Kontraktion des Internus; es handelt sich um eine tonische, nicht um eine prompte reflektorische Kontraktion. Sobald man dem Hund einen Finger in den Anus einführt, geht er sofort 
in halbsitzende Stellung, abduziert den Schwanz und macht gewaltige Anstrengungen der Bauchpresse zur Defäkation.

Weitere Nachuntersuchungen vom 28. VIII. und 1. IX. ergeben den gleicheu Befund und zeigen, daß bezuglich der Auslösung eines Sphincterinternus-Reflexes leichte Schwankungen vorkommen, insofern, als einmal sogleich nach Einführung des Fingers die Atonie eintritt und der Defäkationsmechanismus ausgelöst wird, während das andere Mal eine beschränkte Anzahl (2-3) reflektorischer, trä ger Internuskontraktionen auszulösen sind. Stets tritt aber kurz nach Fingereinführang der charakteristische Entleerungsmechanismus ein.

Nachuntersuchung vom 23. IX. Wunde schön verheilt; Anus geschlossen. Der Finger wird gegen mäBigen Widerstand des Sphincter internus eingeführt. Dabei keine Abwehrbewegungen. Anfänglich eine reflektorische, tonische Kontraktion im Niveau des Analrings. Doch schon nach 10-20 Sekunden tritt Atonie ein und die Darmwand liegt dem Finger auch im Gebiete des Sphinkters nur noch mit ganz geringem Drucke an. $5 \mathrm{~cm}$ oberhalb des Analrings ist der typische Kontraktionsring am Übergang des Rektums in das Colon descendens zu fühlen. Der Hund nimmt eine Stellung ein wie bei der Defäkation. - Ein prompter Analreflex ist weder rom Rektum noch von der Analhaut aus zu erzielen.

Hund Nr. 7. 28. VIII. Morphium- $\Lambda$ thernarkose.

Ausgiebige mediane Iaparotomie. Vorzichen des Colon descendens und sorgfältige Präparation der Nervi hypogastrici, des Plexus hypogastricus und der $\mathrm{N}$. crigentes sive pelvici, unter Vermeidung einer Verletzung oder stärkeren Zerrung. Die Hypogastrici und Erigentes werden zum Zwecke sofortiger Auffindung auf Fadenschlingen gelegt. Vorziehen des Dickdarms, quere Trennung desselben etwas oberhalb seines Überganges ins Rektum. Einbinden eines Pfropfens mit Glasrohr in das untere Darmende und Verbindung desselben mit einem MeBzylinder. Der Iund wird nun nur in leichter Narkose gehalten. Die Analreflexe sind deutlich vorhanden.

I. Messung der Sphinkterenschlußkraft bei intakter Nervenversorgung:

1. Der Hund hält $190 \mathrm{~mm}$ Wasser; bei Übersteigung dieses Druckwertes spritzt er bis zu $135 \mathrm{~mm}$.

2. Es werden wieder $190 \mathrm{~mm}$ gehalten, dann Entleerung bis zu $150 \mathrm{~mm}$.

3. Bei nochmaliger Fullung werden gehalten $200 \mathrm{~mm}$ Wasser. Bei Übersteigung dieses Druckes Fintleerung und zwar wieder bis zu $150 \mathrm{~mm}$ Wasserdruck. -

Jetzt werden die beiden Hypogastrici an den Fadenschlingen hervorgezogen und mit der Schere durchtrennt; die Messung der gehaltenen Flassigkeitsmenge sowie der Druckwerte, bis zu denen die Entleerung erfolgt, ergibt folgendes Resultat:

1. $190-220 \mathrm{~mm}$ - dann Entleerung bis $140 \mathrm{~mm}$.

2. $210 \mathrm{~mm}$ - Entleerung bis $180 \mathrm{~mm}$.

3. $200-210 \mathrm{~mm}$ - Entleerung bis $170 \mathrm{~mm}$.

[Der einzige EinfluB, der hieraus einigermaßen sicher hergeleitet werden kann, nämlich die Unterbrechung des Ausfließens bei einem um $10-50 \mathrm{~mm}$ höheren Wasserdruck, würde sich aus der wohl unbestrittenen, in einer Erweiterung des Sphincter ani internus bestehenden Funktion der Hypogastrici erklären. Durchtrennung hat Wegfall dieser Dilatations- 
wirkung (Hemmung) zur Folge und entsprechend gelingt es dem Sphinkter fruher, den Strom des ausfließenden Wassers zu unterbrechen. -)

Nun werden auch die Nervi erigentis beiderseitig reseziert, um so indirekt den Anteil des von ihnen versorgten Sphincter internus an der Analschlußkraft zu bestimmen.

Diese Messung III ergibt:

1. Es werden gehalten $160 \mathrm{~mm}$, dann Entleerung bis $115 \mathrm{~mm}$;

2. gehalten $160 \mathrm{~mm}$, entlcert bis $110 \mathrm{~mm}$;

3. gehalten $155 \mathrm{~mm}$, entleert bis $110 \mathrm{~mm}$.

Auf Reiz der Analhaut und der Rektalmucosa durch den eingefuhrten Finger erfolgen stets noch reflektorische Kontraktionen, die an Kraft nicht merklich schwächer sind als vor Durchschneidung der N. erigentes s. pelvici.

Jetzt werden die beidseitigen Nervi pudendi von auBen her freigelegt und der Nervus haemorrhoidalis medius beidseitig getrennt, um so auch die spinale Innervation des Sphincter ani externus auszuschalten. Zur größeren Sicherheit wird noch etwas weiter oben der Stamm des Nervus pudendus beidseitig durchschnitten.

Die reflektorischen Kontraktionen des Sphincter ani sistieren natarlich sofort, es tritt ein $1 / 2 \mathrm{~cm}$ breiter Rektalschleimhautsaum zutage; die Schlu Bkraft für Wasser ist $=$ Null, der elastische SchlaB erweist sich also für Flussigkeit als insuffizient.

Auch hier wird konstatiert, daß $5 \mathrm{~cm}$ oberhalb des Anus der Darm fest kontrahiert ist; damit ist neuerdings bewiesen, daB vou dieser Stelle aufwärts eine differente Innervation in Frage kommt. Durch diese tonische Kontraktion des Colon descendens wird ein so fester Schluß bewirkt, daß - wenn man den Pfropfen zurückzieht - eine Wassersäule von $350 \mathrm{~mm}$ gehalten wird. Diese Frscheinung erklärt auch, wieso von Frankl-Hochwart (l. cf.) der Internustonus beim Tiere ohne Rückenmark auf $160 \mathrm{~mm}$ Wasser bestimmt wurde. Man mu\& bei diesen Messungen immer darauf acht geben, daB zwischen Analring und eingebundenem Pfropfen keine tonisch kontrahierte Darmpartis sich befindet, was entweder dadurch vermieden wird, daß man das Rektum und Colon durch Wasserdruck gedehnt erhält oder durch Verschieben des Pfropfens oder Glasrohrs, welches mit dem Meßzylinder in Verbindung steht, bis unmittelbar oberhalb des Analringes. -

Hund Nr. 8. Versuch 5. IX.: Morphium-Äthernarkose.

Mediane Laparotomie; Vorziehen des Colons und stumpfe Präparation der $\mathrm{N}$. hypogastrici und erigentes, die beide auf Fadenschlingen gelegt werden. Quere Trennung des Dickdarms und Einbinden des MeBzylinderschlauches in das Rektum.

Auf Einfließen von Wasser erfolgt Schließreflex.

I. Messung:

Der Hund hält $310 \mathrm{~mm}$ - spritzt bis $260 \mathrm{~mm}$.

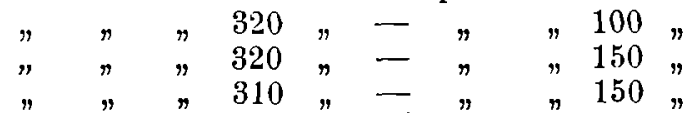

Nun wird der" rechtsseitige $\ddot{M}$. sphincter ani "externus" freigelegt, das anale Drittel des Muskels sorgfältig isoliert und in der Mitte zwischen zwei Ligaturen quer durchtrennt. 
II. Messung:

Der Hand hălt $260 \mathrm{~mm}$ - spritzt bis $100 \mathrm{~mm}$.

Jetzt wird das mittlere Drittel des Muskels isoliert und ebenfalls zwischen zwei Ligaturen durchschnitten.

III. Messung:

Es werden gehalten $140 \mathrm{~mm}$ - dann Entleerung bis $80 \mathrm{~mm}$

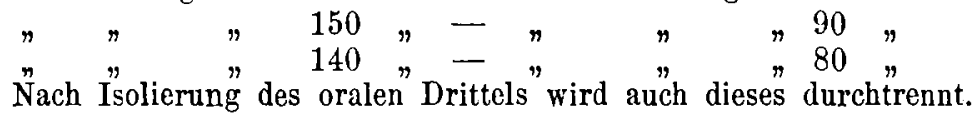

IV. Messung:

Es werden gehalten $120 \mathrm{~mm}$ - dann Entleerung bis $80 \mathrm{~mm}$

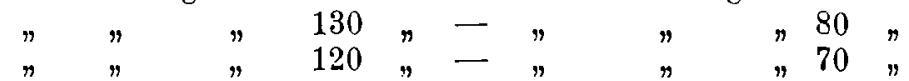

Also macht der linksseitige Externus mit dem intakten Sphincter internus noch einen gewissen SchluB. Die nähere Beobachtung zeigt, daB es sich hier nicht um eine eigentliche "Sphinkterwirkung" handelt, sondern daB der Darm durch die Kontraktion der intakten Externushălfte einfach nach rechts hinübergedrückt und so komprimiert wird.

Jetzt wird auch noch der linksseitige Sphincter externus freigelegt und präpariert. Dabei wird offenbar die Innervation etwas geschädigt, so daB die Kontraktionen nicht mehr energisch erfolgen. Die Messungsdifferenzen für partienweise Trennung des Externus würden daher nur gering sein, und deshalb wird der ganze linksseitige Sphincter externus auf einmal quer durchtrennt. Man konstatiert, daB die reflektorischen Kontraktionen im Niveau des Analrings - und damit zirkuläre Einschnurung des untersuchenden Fingers - sofort aufhören. Entsprechend sinkt die Wassersäule auf Niveau Null. Der Anus zeigt, wie gewöhnlich nach Externusdurchtrennung, einen schmalen Schleimhautsaum. Bevor der linksseitige Sphinkter getrennt wurde, stellte man die Kontinuität des rechtsseitigen durchschnittenen Sphinkters durch Verknüpfung der Ligaturen wieder her. Die Schlußkraft des Sphinkters entsprach einer Wassersäule von $130-150 \mathrm{~mm}$, also nur wenig mehr, als vor der Verknüpfung. Die Erklärung liegt darin, daß durch die quere Trennung des Externus auch die Innervation gestört wurde; nach der Verknüpfung wirkt der Muskel nur noch als elastischer Strang, ohne wesentliche eigene Kontraktionsfähigkeit.

Nach Trennung beider Hälften des Sphincter externus zeigt der Sphincter internus nur noch eine unbedeutende tonische Kontraktion.

DurchreiBen der $\mathrm{N}$. hypogastrici hat keinen sichtlichen, durch Inspektion wahrnehmbaren Effekt auf den Sphincter internus. Nun werden auch noch die $\mathrm{N}$. erigentes durchgerissen: sofort schwindet der Tonus des Sphincter internus, so daB der Anus jetzt etwas offen steht. Der Finger tindet beim Eindringen in das Rektum keinen Widerstand mehr und kann keinerlei tonische Kontraktion auslösen. Scharfe Abgrenzung des schlaffen Rektums gegen den kontrahierten absteigenden Dickdarm!

Hund Nr. 9. 9. IX. Morphium-Äthernarkose.

Mediane Laparotomie; Vorziehen des Dickdarms, Präparation der Hypogastrici und Erigentes, welche auf Fadenschlingen gelegt werden. 
Dann wird der Darm quer durchtrennt, das obere Ende unterbanden, in das untere der Ansatz des MeBzylinderschlauches eingebunden.

Messung der SchlieBkraft des intakten Analrings, in ubblicher Weise:

Die gehaltene Wassersäule miBt 220-250 mm; dann tritt Entleerung ein bis zu einem Druckwert von $150 \mathrm{~mm}$. Wiederholte Versuche ergeben stets dasselbe Resultat.

Jetzt wird beidseitig der Sphincter ani externus freigelegt, das anale Drittel sowohl links wie rechts sorgfältig isoliert und zwischen zwei Ligaturen getrennt.

Der Analring hält jetzt $180-200 \mathrm{~mm}$ Wasser und entleert bei Übersteigung dieses Druckes bis zu Druckwert $100 \mathrm{~mm}$.

Nun wird, wieder beidseitig, das mittlere Drittel des Sphincter externus isoliert und getrennt.

Der Analring hält jetat noch $100 \mathrm{~mm}$. Die Entleerung geht bis zum Druckwert $10 \mathrm{~mm}$. Einmal findet völlige Entleerung statt, einmal Entleerung bis $20 \mathrm{~mm}$.

Es steht jetzt vom ganzen Sphincter externus nur noch das oralste, schwächste Drittel. Auch dieses wird nach Isolierung vom Darm durchschnitten. Sogleich sinkt dic Flüssigkeitssäule auf Null. Für den untersuchenden Finger ist nur noch ein schwacher Internusschlu $B$ nachweisbar.

Bevor das orale Drittel des Externus getrennt wurde, durchreiBt man die Hypogastrici mittelst der Fadenschlinge. Es crfolgt eine bedeutende, reflektorische, tonische Kontraktion des restierenden Sphincter externus und des Sphincter internus; diese Zusammenziehung löst sich nach 20 Sekunden.

Durchreißung der Erigentes gibt keinerlei deutlichen Effekt. Ein event. Effekt auf den Sphincter internus, der ja von den $\mathbf{N}$. erigentes versorgt wird, kann wegen der noch stehenden Portion des Sphincter externus nicht zur Geltung kommen (Nachlassen des Tonus). Man beobachtet auch hier wieder, daß hinsichtlich Lage des Pfropfens oder Schlauches im Rektum die größte Aufmerksamkeit zu wahren ist. Sobald nämlich der AnalschluB nicht mehr so kräftig ist, daB eine große zur Dehnung des Rektums und Colons führende Wassersäule gehalten wird, kontrahiert sich der Darm tonisch und kann so unter Umständen bedeutende Wassermengen halten, die dann fälschlich als Ãquivalente der Sphinkterenschlußkraft gedeutet werden, während faktisch diese Kraft nur noch ganz minimal ist.

Der Hund hatte eine relativ geringe Schlußkraft, weil er zu viel Morphium bekam $(0,06 \mathrm{~g})$.

II und Nr. 10. 10. IX. Morphium (0,03 g). Äthernarkose. Mediane Laparotomie. Die Hypogastrici und Erigentes werden in diesem Falle nicht präpariert, um jede event. mögliche Läsion auszuschlieBen. Vorziehen des Rektums und quere Trennung. Einbinden eines Schlauches in das Rektum und Verbindung mit dem Mebzylinder.

Der ganze Sphinkterring hält:

$300 \mathrm{~mm}$, Entleerung bis $180 \mathrm{~mm}$

320

300

$" \quad " \quad \Rightarrow 180 "$

Nun wird der Sphincter externus unter Vermeidung jeder Nervenläsion 
sorgfältig freigelegt, and beidseitig das anale Drittel isoliert. Trennung zwischen zwei Ligaturen. gehalten:

Messung (Mittelwerte aus wiederholten Messungen): es werden

$240 \mathrm{~mm}$. - Entleerung bis $150 \mathrm{~mm}$. Isolierung des mittleren Drittels und Trennung zwischen zwei Ligaturen.

Messung: es werden gehalten:

$130-140 \mathrm{~mm}$; dann vollständige Entleerung bei Übersteigung dieses Druckes. Ganz vereinzelt werden $10-15 \mathrm{~mm}$ Wasser nach der Entleerung gehalten.

Nun wird zunächst links das stehengebliebene orale Drittel getrennt. Sogleich sinkt die AnalschluBkraft für Wasser auf Null. Auch nachdem dieses Drittel des Externus durch Verknupfung der Ligaturen wieder vereinigt ist, hält der Analring keine Flüssigkeit zurück. Nachdem auch die aboralen Teile des Sphincter externus wieder vereinigt sind, beträgt die Schlubiraft wieder 70-80 mm Wasser. Die Entleerung geht bis zu 10 bis $20 \mathrm{~mm}$; event. ist sie auch eine vollständige.

Es werden jetzt beidseitig die sämtlichen Externusfasern wieder getrennt. Man konstatiert nun, daB der Sphincter internus noch einen Schlußreflex macht auf entsprechenden Reize; zugleich kontrahieren sich die Externusstümpfe. Aber eine meBbare Wassersäule wird nicht mehr gehalten; das Rektum entleert sich vollständig.

Fingereinführung zeigt, daB das Rektum tonisch kontrahiert ist. Man fühlt auch die umschriebene Kontraktionszone des Spincter internus, solange überhaupt der tonische Kontraktionszustand des Rektums andauert.

Als wesentliche Beobachtung in diesem Experimente ist hervorzuheben, daB der reflektorische SchluBmechanismus des Analrings so lange besteht, als noch eine irgend wesentlicher zirkuläre Portion des Sphincter externus zurlickgelassen ist. Zurücklassung eines Drittels Sphincter externus auf einer Seite genügt nicht mehr, eine Wassersäule zuruckzuhalten; es tritt sofort Entleerung des Mastdarms ein.

Der Hund hielt mehr Wasser zurück mit seinem Analring, als das vorige Versuchstier, weil mit Rücksicht auf die bekannte Tatsache, da $B$ Morphium den Sphinktertonus herabsetzt, eine um die Hälfte kleinere Dosis Morphium verabreicht worden war. -

29. IX. Es wird bei dem Hunde Nr. 5 in leichter Morphium-Äthernarkose eine Messung der Sphinkterenschlußkraft in üblicher Weise gemacht. Das Flüssigkeitsniveau sinkt stets sofort auf Null. - Die anschlieBend ansgefuhrte Autopsie zeigt die untersten 5 cm des Rektums im Zustande der Dilatation, während der nach oben anschlieBende Dickdarm sebr gut kontrahiert ist. Der Sphincter externus ist makroskopisch hochgradig atrophiert; der Muskel stellt nur einen ca. $2 \mathrm{~mm}$ dicken, etwa $\left.1\right|_{2} \mathrm{~cm}$ breiten Strang dar. Weitere Details sollen durch die histologische Untersuchung festgestellt werden (vgl. S. 97). -

Auch IIund Nr. 6 wird in leichter Morphium- $\mathrm{A}$ thernarkose laparotomiert, der Dickdarm vorgezogen, eröffnet, und ein mit dem MeBzylinder verbundenes Gummirohr in das Rektum eingeschoben. Die Messung ergibt auch hier stets sofortigen Abfall der Flüssigkeitssäule auf Niveau Null, 
was mit den früheru Resultaten äbereinstimmt, nach denen die Schlußliraft des Sphincter internus für Flüssigkeiten in Narkose gleich Null ist.

Anschließend Autopsie: Iängsschnitte durch das Rektum, welche den Sphincter externus quer treffen, zeigen, daB nur oben und unten (dorsal und ventral) der Sphincter externus erhalten ist, im Zustande deutlicher Inaktivitätsatrophie (im Vergleich zum Befund bei der Opcration), während seitlich beidseitig keine Muskelfasern nach außen vom Sphincter internus nachweislich sind; an Stelle des Sphincter externus findet sich nur Narbengewebe. -

\section{Literaturverzeichnis.}

(Wir geben die Literatur nur an, soweit sie von uns benutzt wurde und Fragen betrifft, die im Text behandelt wurden. Für die vollständige Literatur siehe die Arbeit v. Frankl-Hochwarts und Fröhlichs sowie das Handbuch von Nagel und die Ergebnisse der Physiologie von Asher und Spiro, Biophys. 1.)

1. Bayli B, W. M. u. E. H. Starling. Journ. of Physiol. 24, 1899 u. 26, 1901.

2. Starling, E. H., Ergebnisse d. Physiol. Herausgeg. von Asher u. Spiro. Biophysik 1, 1902.

3. Magnus, R. Pflügers Arch. 102 u. 103, 1904; 108, 1905; 111, 1906.

4. Prutz, W., u. A. Ellinger. Arch. f. klin. Chir. 67, H. 4, 1902 u. 72 , H. 2, 1904.

5. Cannon, W. B. Americ. Journ, of Physiol. 6, 1902 u. 12, 1904.

6. Bunch, J. L. Journ. of Physiol. 25, 1900.

7. Grützner, P. Deutsche med. Wochenschr. 1894 n. 1899; Pflügers Arch. $\mathbf{7 1}, 1898$.

8. Hemmeter, J. O. Arch. f. Verdaungskrankh. 8, 1902.

9. Exner, A. Pflügers Arch. 89, 1902.

10. Elliot, T. R. and E. Barclay-Smith. Journ. of Physiol. 31, 1904.

11. Magnus, R. Zentralbl. f. Physiol. 19, $190 \overline{\text { o. }}$

12. Langley, J. N. and R. Magnu s. Journ. of Physiol. 33, 1905̃.

13. Elliot, T. R. Journ. of Physiol. 31, 1904.

14. Cohnheim, Otto, Die Physiologie der Verdauung und Aufsaugung (in Nagels Handbuch d. Pbysiol. des Menschen).

15. v. Frankl-Hochwart, L. u. Alfr. Fröhlich. Über Tonus u. Innervation der Sphinkteren des Anus. Pflügers Arch. 81, 1900.

16. Eckhardt, C., Beiträge zur Anat. u. Physiol. 3.

17. Langley and Anderson. Journ. of Physiol. 17, 1894; 18, 19; 20.

18. Fellner. Med. Jabrbücher d. Gesellschaft d. Ärzte. Wien 1883; Arch. f. d. ges. Physiol. 56, H. 10-12, 1894.

19. Waldeyer, Das Becken.

20. Goltz, F. Pflügers Arch. 8, 1874.

21. Goltz, F. u. J. R. Ewald. Pfügers Arch. 63, 1896.

22. Müller, L. R. Deutsche Zeitschr. f. Nervenheilk. 21, 1901.

23. Arlonig, S. et Ed. Chantre. Compt. rend. de l'Acad. d. Sciences 127; Compt. rend. des Séances de l'Acad. des Sciences 1897. 
24. Langley, J. U., Das sympath. u. verwandte Nerv.Systeme der Wirbeltiere. Ergebn. d. Physiol. II:2. Sep.-Abdr.

25. Pal, J. Wiener klin. Wochenschr. 1896, Nr. 12; 1897, Nr. 2.

26. Budge, J., ய̈ber das Centrum genito-spinale. Virchow Arch. 15; N. F., 5.

27. Masius. Journ. de l'Anat. et. de la Physiol. 6, Nr. 1.

2S. Kocher, Th., Die Verletzungen der Wirbelsäule, zugleich als Beitrag zur Physiol. des menschl. Rückenmarks. Mitteil. a. d. Grenzgeb. d. Med. u. d. Chirurgie.

29. v. Bechterew, W. Neurolog. Zentralbl. 1893.

30. I ucceschi. Riv. di Patol. nerv. e ment. B, Nr. 6, 1898.

31. Merzbacher, L. Pflügers Arch. 92, 1902.

32. v. Frankl-Hochwart u. Fröhlich. Jahrbücher f. Psychiatr. u. Neurologie 1902 .

33. v. Monakow, C., Ergebnisse d. Physiol. I. Biophysik.

34. v. Frankl-Hochwart u. Fröhlich. Wiener klin. Rundschau 1901. Nr. 41.

35. Merzbacher, L. Pflügers Arch. 92. 1002.

36. Levandowsky, M. u. P. Schultz. Zentralbl. f. Physiol. 17, 1903.

37. Sahli. Lehrbuch der klin. Untersuchungsmethoden. 4. Aufl.

38. Grützner, P. Ergebnisse d. Physiol. @, 1904.

39. Landois. Lehrbuch der Physiol. d. Menschen. 11. Aufl. bearb. von Rosenmann, 1905.

40. Langley and Dickinson. Journ. of. Physiol. 11.

41. Ellenberger u. Baum, Anatomie des Hundes.

42. Bilfiuger, Bernh., Über plast. Operationen bei Schlußunfähigkeit des Sphincter ani. Diss. Kiel 1903.

43. Kehrer, Über eine neue Methode der Sphinkterplastik. Deutsche med. Wochenschr. 1850, Nr. 33.

44. Rotter, J., Die Krankheiten des Mastdarms u. des Afters. Handbuch d. prakt. Chir., v. Bergmann u. v. Bruns.

45. Roussy, (r. et J. Rossi. Troubles de la miction et de la defécation consécutifs aux lésions expérimentales du cône terminal ou de la queue de cheval chez le singe. Compt. Rend. Soc. de Biolog. 64, 1908.

46. Gegenbaur. Anatomie des Mensehen VII. Aufl.

47. Toldt. Anatom. Atlas II. Aufl.

4S. Hermann. Lehrbuch der Physiol. XII. Aufl. 